\title{
Les activités biochimiques des Penicillium utilisés en fromagerie
}

\author{
Jutta CERNING *, J.C. GRIPON *, G. LAMBERET ** et J. LENOIR ** \\ * I.N.R.A., Laboratoire de Biochimie et de Technologie laitières \\ 78350 Jouy-en-Josas (France) \\ ** I.N.R.A., Laboratoire de Technologie, I.N.A. Paris-Grignon \\ 78850 Thiverval Grignon (France)
}

\begin{abstract}
Résumé
Le $P$. camemberti et le $P$. roqueforti constituent respectivement la moisissure superficielle dominante des fromages de type camembert et la moisissure interne des fromages à pâte persillée. Ces deux espèces appartiennent à la section des asymmetrica qui comporte cinq sous-sections dont les lanata ( $P$. camemberti) et les velutina ( $P$. roqueforti). Toutes les souches ne possèdent pas les mêmes caractéristiques et diverses formes peuvent être reconnues parmi les souches de chacune des deux espèces. Les comportements physiologiques de $P$. camemberti et de $P$. roqueforti sont assez différents; la vitesse de croissance du premier est faible, celle du deuxième est plus rapide. La sensibilité au sel du $P$. camemberti est très faible, le $P$. roqueforti est stimulé par des faibles teneurs en sel. La capacité des deux espèces à consommer l'acide lactique et les lactates aboutit à la désacidification des pâtes fromagères et entraîne des répercussions majeures en fromagerie.

$P$. camemberti et $P$. roqueforti possèdent des systèmes protéolytiques présentant entre eux de très grandes analogies et synthétisent tous deux une aspartyl protéase et une métalloprotéase, et des exopeptidases (aminopeptidases et carboxypeptidases). Le niveau de production des diverses enzymes protéolytiques de $P$. camemberti étudié sur un assez grand nombre de souches varie relativement peu d'une souche à l'autre. L'action in vitro des enzymes protéolytiques sur les caséines met en évidence une analogie d'action entre les enzymes de $P$. camemberti et $P$. roqueforti. Cette analogie est plus marquée pour les aspartyl protéases que pour les métalloprotéases. La protéolyse est qualitativement assez proche dans les camemberts et les fromages à pâte persillée et reflète bien l'homologie observée au niveau des systèmes protéolytiques des deux moisissures. Toutefois l'hydrolyse est plus poussée dans les pâtes persillées.

$P$. roqueforti produit deux lipases, l'une ayant un optimum d'action à $\mathrm{pH} 6,5$ (lipase acide), l'autre à $\mathrm{pH} 8,0-8,3$. $P$. camemberti ne produit qu'une seule lipase de $\mathrm{pH}$ optimal d'action alcalin. Les lipases alcalines des deux espèces possèdent des caractéristiques d'action assez semblables, toutes deux sont plus actives sur la tributyrine que sur les autres triglycérides homogènes et leurs activités relatives sur trioléine sont proches de $20 \%$ de l'activité sur tributyrine. Elles se différencient par leur action sur la tricapryline et la tricaprine avec des vitesses d'hydrolyse relatives de 91 et $62 \%$ pour la lipase de $P$. roqueforti et de 65 et $27 \%$ pour celle de $P$. camemberti. Le pH est un facteur important de production de l'une ou l'autre lipase de $P$. roqueforti, il en va de même pour la lipase alcaline de $P$. camemberti. L'activité lipasique dans les
\end{abstract}


fromages se manifeste surtout au voisinage du mycélium, aussi les acides gras libres sontils localisés essentiellement dans la partie centrale des bleus et sous la croûte dans les camemberts. Les taux d'acides gras libres sont particulièrement élevés dans les deux types de fromages. L'emploi de souches différentes de $P$. roqueforti conduit à des profils d'acides gras volatils différents dans les bleus, probablement en raison des quantités respectives des deux lipases. La part des Penicillium dans la dégradation des acides aminés est difficile à préciser, mais il a été observé que les moisissures sont des agents responsables de la décarboxylation et de la dégradation de l'arginine.

Comme un certain nombre de moisissures appartenant à diverses espèces, $P$, roqueforti et $P$. camemberti possèdent une voie métabolique originale conduisant, à partir des acides gras saturés à chaîne courte et moyenne, à des cétones. Cette voie se greffe sur la voie normale de la $\beta$-oxydation des acides gras.

Les méthylcétones représentent une fraction majeure des composés volatils des fromages et jouent un rôle très important dans l'acquisition des qualités organoleptiques et en particulier dans le cas des pâtes persillées.

Mots clés : Penicillium roqueforti - Penicillium camemberti - Taxonomie - Physiologie Aspartyl protéases - Métalloprotéases - Carboxypeptidases - Aminopeptidases - Lipases alcalines - Lipase acide - Production d'enzyme - Phosphohydrolase - Lipolyse - Protéolyse - Méthylcétones - Fromages - Affinage.

\section{Summary}

\section{Biochemical activities of Penicillium used in cheese making}

Penicillium camemberti and $P$. roqueforti represent respectively the main superficial mold of camembert type cheese and the internal mold of blue veined cheese. These species belong to the asymmetrica section which is divided into five sub-sections. $P$. camemberti belongs to one of these groups called lanata, $P$. roqueforti to the one called velutina. All strains do not possess the same properties and various forms can be recognized among the strains of each of the two species. The physiological behaviour of $P$. camembert $i$ and $P$. roquefort $i$ are quite different, the first one has a slow growth rate, the latter grows faster, $P$. camemberti is not very salt sensitive. $P$. roqueforti is stimulated by small salt quantities. The ability of the two mold species to metabolize lactic acid and lactate results in an increase of $\mathrm{pH}$ of the cheese which has important consequences in cheese making.

$P$. camemberti and $P$. roqueforti have quite similar proteolytic systems, they produce each one aspartyl proteinase and one metalloproteinase and exopeptidases (aminopeptidase and carboxypeptidases). The production level of the different proteolytic enzymes of $P$. camemberti, studied on a large number of strains, was shown to vary relatively little from one strain to the other. In vitro action of the proteolytic enzymes of $P$. camemberti and $P$. roqueforti on caseins shows that the enzymes have a similar action, the similarity being more pronounced for the aspartyl proteinases than for the metalloproteinases. Proteolysis in camembert and blue veined cheese is qualitatively very close and this reflects the similarity of proteolytic system of the two molds. However casein hydrolysis is more pronounced in blue veined cheese.

$P$. roqueforti produces two lipases, one has a $\mathrm{pH}$ optimum at 6.5 (acid lipase), the other at 8.0-8.3 (alkaline lipase). $P$. camemberti produces one lipase only with a $\mathrm{pH}$ optimum at alkaline values. The alkaline lipases of the two species have similar properties, both are more active on tributyrine than on other homogeneous triglycerides and their relative activities on triolein are close to $20 \%$ of the activity on 
tributyrin. They differ by their action on tricaprylin and tricaprin with relative hydrolysis rates of 91 and $62 \%$ for the $P$. roqueforti lipase and 65 and $27 \%$ for the $P$. camemberti lipase. The $\mathrm{pH}$ is an important factor which affects the production of both lipases of $P$. roqueforti and of the alkaline lipase of $P$. camemberti. Lipolytic activity in cheese is observed essentially close to the mycelium. Therefore free fatty acids are located primarily in the center of blue veined cheese and under the surface of camembert. The quantities of free fatty acids are particularly high in the two types of cheese. The use of various $P$. roquefort $i$ strains results in different votatile fatty acid profils probably because of the respective quantities of the two lipases.

It is difficult to precise which part Penicillium play in the amino acid degradation, but it has been observed that the mold is responsible for the decarboxylation and degradation of arginin.

$P$. roqueforti and $P$. camemberti, just like molds from other species produce ketones from short and medium chain saturated fatty acids via the $\beta$-oxydation pathway. Methylketones represent the major fraction of volatile components in cheese and play an important role for the organoleptical qualities, particularly for blue veined cheese.

Key words : Penicillium roqueforti - Penicillium camemberti - Taxonomy - Physiology - Aspartyl proteinase - Metalloproteinase - Carboxypeptidase - Aminopeptidase Alkaline lipase - Acid lipase - Enzyme production - Methylketones - Phosphohydrolase - Lipolysis - Proteolysis - Cheese - Ripening.

\section{Introduction}

Le développement d'une flore fongìque superficielle ou interne constitue une des caractéristiques majeures de divers fromages et, au sein de cette flore, deux espèces, Penicillium camemberti et $P$. roqueforti, sont particulièrement importantes en raison du rôle déterminant qu'elles jouent au cours de la maturation.

$P$. camemberti forme le feutrage blanc des fromages de types camembert, brie, carré de l'est. Il est présent à la surface des bondons de Neufchâtel et il constitue la moisissure superficielle dominante de la plupart des fromages de chèvre à croûte fleurie.

$P$. roqueforti est la moisissure interne des bleus, qu'il s'agisse de fromages de lait de vache, tels le bleu d'Auvergne, le bleu de Bresse, le gorgonzola, le bleu danois, le stilton..., ou de fromages de lait de brebis, comme le roquefort.

Chacune des deux espèces représente un élément essentiel de la personnalité des fromages concernés. Par formation d'une croûte superficielle ou par création de l'aspect persillé, elles leur confèrent une «touche» originale. Par leurs aptitudes biochimiques, elles participent aux grands phénomènes de l'affinage et elles contribuent puissamment à la détermination des caractères rhéologiques et organoleptiques des pâtes.

Les activités biochimiques de $P$. camemberti et de $P$. roqueforti ont fait l'objet de nombreux travaux mais les revues portant sur le sujet sont rares ou anciennes (BAKALOR, 1962 a et b ; COGHIL, 1979). Au cours des quinze dernières années, nos laboratoires se sont attachés à en préciser la nature ou le niveau. Aussi nous parait-il opportun de faire le point de nos connaissances sur les poten- 
tialités de deux microorganismes qui sont, aujourd'hui, largement utilisés en fabrications fromagères et qui peuvent être appelés demain à assurer une production d'enzymes en vue de la mise en œuvre de nouvelles technologies de l'affinage.

\section{Taxonomie et physiologie}

\section{A. Taxonomie}

Les premières études concernant le genre Penicillium remontent au début du siècle. A cette époque, on avait tendance à répertorier de nouvelles espèces sur la base de quelques différences morphologiques parfois minimes. Aussi a-t-on connu pendant longtemps de nombreuses appellations pour la même moisissure. Actuellement, la taxonomie du genre Penicillium repose sur les travaux de RAPER et Tном (1949) et sur certaines mises au point plus récentes qui ont cherché à normaliser les diverses dénominations.

Sur la base de la forme en pinceau des organes de fructification RAPER et Тном classent le genre Penicillium, dont on connaît environ 1000 espèces (PITT, 1979), en quatre sections (tabl. I). Les Penicillium utilisés en fromagerie appartiennent à la section des asymmetrica, laquelle comporte cinq sous-sections, dont les lanata et les velutina.

TABLEAU I

Classification des Penicillium selon RAPER et THOM (1949) Classification of Penicillia according to RAPER and THOM (1949)

\begin{tabular}{|c|c|c|}
\hline Sections & Sous sections & Espèces \\
\hline $\begin{array}{c}\text { Monoverticillata } \\
\text { Symmetrica } \\
\text { Asymmetrica }\end{array}$ & $\begin{array}{c}\text { Divaricata } \\
\text { Velutina } \\
\text { Lanata } \\
\text { Funicolosa } \\
\text { Fasciculata }\end{array}$ & P. roqueforti \\
\hline Polyverticillata & & Pamberti \\
\hline
\end{tabular}

Section $^{\star}$ : sur la base de la structure du pinceau.

Penicillium camemberti relève du groupe des lanata; les thalles sur milieu gélosé ont un aspect floconneux et les conidiophores prennent généralement naissance au niveau d'hyphes aériens. 
Jusqu'à ces dernières années on distinguait deux espèces : $P$. caseicolum (anciennement $P$. candidum), dont les colonies restent blanches, et $P$. camemberti (anciennement $P$. album) qui prend une teinte vert pâle après une dizaine de jours. SAMSON et al. (1977) ont estimé qu'une telle distinction n'était pas justifiée et à l'heure actuelle ces espèces sont réunies sous le nom de $P$. camemberti THOM (PITT, 1979).

Cependant toutes les souches de $P$. camemberti ne possèdent pas exactement les mêmes caractéristiques et Moreau (1979) a proposé de les classer en quatre formes :

- la forme Neufchâtel, souches sauvages, vigoureuses, à croissance rapide, donnant un feutrage épais, blanc jaunâtre ; et ras ;

- la forme «à poils courts ", souches à croissance rapide, à thalles serrés élevés ;

— la forme à "poils longs », souches à croissance lente, à thalles lâches et

- la forme à thalles floconneux, d'abord blancs, puis gris vert (variété camemberti sensu stricto).

$P$. camemberti n'est pas la seule espèce à former des thalles blancs; d'autres Penicillium ayant cet aspect peuvent contaminer les produits laitiers, par exemple $P$. thomii, $P$. nalgiovensis, $P$. verrucosum (Moread, 1979).

Penicillium roqueforti appartient au groupe des velutina; le mycélium est en grande partie submergé, la partie aérienne est constituée de conidiophores partant directement du substrat; les pinceaux se trouvent au même niveau et donnent un aspect velouté à la colonie.

Il est caractérisé par des conidiophores à parois rugueuses et verruqueuses. Contrairement à $P$. camemberti dont l'habitat se limite à la surface des fromages, $P$. roqueforti est largement répandu. L'espèce est distincte de $P$. glaucum, une dénomination ancienne dont l'usage doit être proscrit (CHOIsY et al., 1984).

$P$. roqueforti a une croissance rapide; les conidies sont bleu vert soutenu; les revers de culture sont verdâtres avec des zones plus sombres; les cultures sont inodores. Sa morphologie paraît plus variée que celle de $P$. camemberti, et cette hétérogénéité semble encore plus nette au plan biochimique que morphologique (FoURNeT, 1971). On a parfois confondu $P$. roqueforti avec $P$. verrucosum var. cyclopium. Toutefois, ce dernier a généralement de plus petites conidies, les conidiophores sont plus minces, les verrues plus petites et surtout il produit une forte odeur terreuse, alors que $P$. roqueforti est sans odeur (MOREAU, 1980 ; PHILIPP, 1981). Par ailleurs, dans une étude comparée des caractères physiologiques et culturaux des deux espèces, VEAU et al. (1981) proposent une culture en milieu à l'acétate de sodium sur lequel seul $P$. roqueforti est inhibé.

Comme pour $P$. camemberti, diverses formes ont été distinguées (MOREAU, 1980) et, à côté de la forme bleu vert, on reconnaît :

- sous le nom de variété viride, des souches de couleur vert jaunâtre plus claire qui sont surtout utilisées pour la fabrication des fromages de gorgonzola ; fromages ;

- des formes brunes, isolées de grains d'orge, qui peuvent contaminer les

- des mutants blancs obtenus par irradiation aux rayons U.V. d'une souche verte normale. 


\section{B. Physiologie}

Comparé à d'autres espèces, $P$. camemberti a une faible vitesse de croissance ; il forme des colonies de $25-35 \mathrm{~mm}$ de diamètre sur extrait de malt gélosé en 2 semaines à $25^{\circ} \mathrm{C}$ (PITT, 1979). Sa température optimale de développement sur extrait de malt est de 20 à $25^{\circ} \mathrm{C}$; il pousse encore à $5{ }^{\circ} \mathrm{C}$ mais non à $37^{\circ} \mathrm{C}$. Le temps nécessaire à la germination de $50 \%$ de spores sur extrait de malt à $22^{\circ} \mathrm{C}$ et à $\mathrm{pH} 6,5$ est de 15 à 25 heures (CHOIsy et al., 1984). La tolérance de la moisissure aux variations de $\mathrm{pH}$ est assez limitée. La plupart des souches se développent très bien de $\mathrm{pH} 3,5$ à 6,5 et certaines, en petit nombre, supportent des valeurs de $\mathrm{pH}$ supérieures à 7 (JACQUET et al., 1955). Actuellement, afin d'assurer une bonne couverture des fromages en fin d'affinage, les souches sélectionnées sont aptes à se développer en milieu alcalin.

La sensibilité au sel est assez faible mais variable selon les souches. En culture sur lactosérum à $\mathrm{pH} 4,7$, la croissance est retardée en présence de $10 \%$ de sel et le phénomène s'amplifie aux plus fortes concentrations (GUEGUEN et Voisin, données non publiées). A partir de $20 \%$ de sel, la plupart des souches sont inhibées et à la concentration de $25 \%$ l'inhibition est complète. En milieu liquide l'optimum de développement est obtenu en absence de sel alors qu'en milieu solide des teneurs de 1 à $2 \%$ favorisent la croissance (CHOIsY et al., 1984).

Le comportement physiologique de $P$. roqueforti est sensiblement différent. Sa vitesse de croissance est plus rapide; en 1 semaine à $25^{\circ} \mathrm{C}$ il forme des thalles de 40 à $70 \mathrm{~mm}$ de diamètre. La moisissure est apte à se développer à basse température bien que sa température optimale soit proche de $35-40^{\circ} \mathrm{C}$ (CHoIsY et al., 1984). Le pH optimal de croissance est voisin de 4 mais l'espèce tolère de grandes variations de $\mathrm{pH}: 3$ à 10,5 sur milieu synthétique. Cette aptitude permet de la distinguer des espèces voisines, en particulier, par addition de $0,5 \%$ d'acide acétique au milieu Czapek-Dox amenant le pH à 3,4 (ENGEL et TEuber, 1978). De même, elle peut se développer en présence de $5 \%$ d'acide lactique (MoreaU, 1980 ; Philipp, 1981).

De faibles teneurs en sel stimulent la germination des spores de $P$. roqueforti et en milieu acide la moisissure tolère d'assez fortes concentrations. Cultivé sur caillé, une diminution appréciable de croissance se manifeste aux environs de 5 à $6 \%$ de sel (Moreau, 1980 ; Godinho et Fox, 1981 a ; Philipp, 1981), mais ce seuil peut varier selon les souches. L'inhibition semble complète à partir de $15 \%$ de sel (PhilipP, 1981), le seuil limite de tolérance pourrait même se situer à $20 \%$ (FORGE et al., 1977).

$P$. roqueforti est, comme $P$, camemberti, une moisissure aérobie, cependant, contrairement à cette dernière, elle se cultive bien en présence d'un faible taux d'oxygène $(5 \%)$. Une expérience sur la composition du mélange gazeux dans le centre d'un fromage bleu a révélé des proportions de 2,5 à $7 \%$ d'oxygène et 21 à $41 \%$ de gaz carbonique. Il est d'ailleurs possible que ce soit plutôt la tolérance au $\mathrm{CO}_{2}$, et non un besoin limité en oxygène, qui explique les possibilités de développement de la moisissure à l'intérieur du fromage (PHilıpP, 1981).

Les deux espèces peuvent métaboliser un grand nombre de substances organiques et inorganiques. Leur capacité de consommer l'acide lactique, entraînant la désacidification de la pâte, joue un rôle majeur en fromagerie. La croissance de $P$. roqueforti est favorisée par la présence d'arginine, en revanche, les acides aminés soufrés ont un effet défavorable (Gottlieb, 1946; Philipp, 1981). Le 
sulfate d'ammonium est une bonne source d'azote pour la sporulation et la croissance ; l'addition d'oligo-éléments augmente le rendement en poids de mycélium ; les vitamines sont sans effet. La plupart des glucides sont utilisés comme source de carbone par les deux espèces (Meyers et Knight, 1958 ; Philipp, 1981). Pour $P$. camemberti, il a été observé que la présence dans le milieu de culture d'azote peptidique, de phosphates, de magnésium et de divers oligo-éléments minéraux était favorable à la croissance (LENOIR et al., 1973).

\section{Aptitude à la désacidification des caillés}

$P$. camemberti et $P$. roqueforti sont capables d'utiliser l'acide lactique et les lactates comme sources de carbone et cette utilisation se traduit par une neutralisation des pâtes fromagères.

L'exemple de $P$. camemberti et des caillés de camembert est à cet égard particulièrement démonstratif. L'allure des courbes d'évolution du $\mathrm{pH}$ en surface et au centre du fromage au cours de l'affinage (fig. 1) met clairement en évidence une remontée soudaine du $\mathrm{pH}$ superficiel au $6^{\mathrm{e}}-7^{\mathrm{e}}$ jour, moment où se forme le feutrage mycélien (LENOIR, 1962).

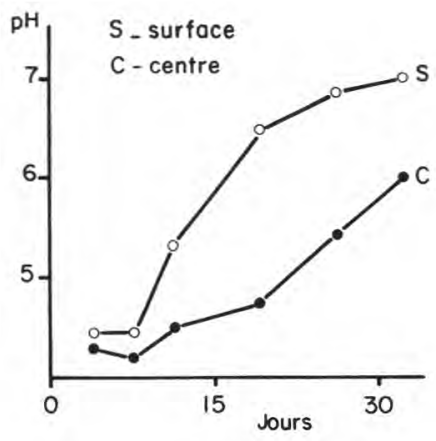

Fig. 1

Evolution du pH au cours de la maturation du camembert. (LENoIR, 1962 a).

Change of $p H$ during camembert ripening. (LENOIR, $1962 a$ ).

La neutralisation du caillé a des incidences très marquées sur la texture de la pâte, l'activité des enzymes et la répartition des minéraux au sein du fromage (Le GRAET et al., 1983 ; VAsSAL et al., 1986).

Avec la remontée du $\mathrm{pH}$, il se produit un assouplissement et une homogénéisation de la pâte, qui sont probablement liés à une modification des interactions 
électrostatiques concernant les protéines et, peut-être aussi, à une augmentation des teneurs en eau et en calcium de la partie superficielle des fromages.

L'augmentation du $\mathrm{pH}$ au-dessus de 6 tend à favoriser l'action de certaines enzymes. Il en est ainsi notamment pour la métalloprotéase et la lipase de la moisissure, ainsi que pour la plasmine du lait dont l'action peut s'accentuer en fin d'affinage. En revanche, l'aspartyl protéase de $P$. camemberti voit son activité réduite et il s'ensuit un moindre risque de développement d'amertume (VASSAL et GRIPON, 1984).

La migration du calcium et du phosphate vers la partie superficielle du camembert qui est observée au cours du développement du Penicillium pouvait être attribuée à un pouvoir séquestrant de la moisissure. En réalité, il apparaît que cette migration est due à l'augmentation du $\mathrm{pH}$ et à la formation en surface de phosphate tricalcique insoluble (LE GRAET et al., 1983). II a d'ailleurs été observé que la croûte d'un camembert affiné renferme près de $80 \%$ du calcium total du fromage.

Une autre conséquence de la désacidification de la partie externe de la pâte est l'implantation d'une flore bactérienne acido-sensible, formée principalement de microcoques et de corynébactéries, qui joue elle-même un rôle important dans le développement de la saveur et de l'arôme du fromage.

\section{Protéolyse et enzymes protéolytiques}

Les deux espèces possèdent des systèmes protéolytiques complets, présentant entre eux de très grandes analogies, avec deux endopeptidases, une aspartyl protéase et une métalloprotéase, et des exopeptidases, aminopeptidases et carboxypeptidases.

\section{A. Les aspartyl protéases}

Ces enzymes, encore appelées protéases acides en raison de leur $\mathrm{pH}$ optimal d'action, ont été mises en évidence pour $P$. roqueforti (Zevaco et al., 1973; MOLDER et al., 1974) et $P$. camemberti (LenOIR et AUBERger, 1977 a ; LeNoIR et al., 1979). Elles sont produites dans les cultures en milieu tamponné à $\mathrm{pH} 4,0$. La protéase de $P$, roqueforti a été purifiée par précipitation au sulfate d'ammonium puis par chromatographie sur colonnes de Biogel P100 et de DEAE cellulose (ZEVACo et al., 1973). L'enzyme de $P$. camemberti a été d'abord concentrée par ultrafiltration et ensuite purifiée par filtration sur Sephadex G75 et chromatographie sur DEAE cellulose (LENOIR et al., 1979). Les enzymes ainsi isolées étaient homogènes en électrophorèse à $\mathrm{pH}$ alcalin ou acide.

Le poids moléculaire de ces deux protéases est du même ordre de grandeur (33 000 à 35000 ) et leur composition en acides aminés est comparable et proche de celle d'autres protéases acides déjà connues. Elles présentent, comme la protéase acide de $P$. janthinellum (CunNigham et al., 1976), une forte proportion de résidus acides par rapport aux résidus basiques; elles ne contiennent pas de méthionine et le nombre de résidus cystéyle est faible. L'enzyme de $P$. camemberti se distingue toutefois de celles synthétisées par d'autres Penicillium par un nombre plus élevé de résidus proline (19 contre 10 pour $P$. roqueforti). La présence 
d'une fraction glycosylée, entraînant un poids moléculaire plus élevé (de l'ordre de 40000 à 45000 ), a été observée pour certaines souches de $P$. roqueforti (Molder et al., 1974 ; Houmard et RAYMOND, 1979).

Les enzymes des deux espèces présentent un $\mathrm{pH}$ optimal d'action sur l'hémoglobine proche de $\mathrm{pH} \mathrm{3,5;} \mathrm{avec} \mathrm{la} \mathrm{caséine} \mathrm{il} \mathrm{existe} \mathrm{un} \mathrm{premier} \mathrm{optimum} \mathrm{à} \mathrm{pH} 3,8$ $(P$. roqueforti) ou 3,5 (P. camemberti) et un optimum principal proche de $\mathrm{pH} 5,0$ pour $P$. camemberti et de 5,5 pour $P$. roqueforti (fig. 2 ).

La zone de stabilité maximale des deux enzymes s'étend de $\mathrm{pH} 3,5$ à $\mathrm{pH} 5,5$ $\left(P\right.$. camemberti) ou $\mathrm{pH} 6,0\left(P\right.$. roqueforti) (tabl. II). Un maintien à $40^{\circ} \mathrm{C}$ pendant une heure à $\mathrm{pH} 3,2$ ou $\mathrm{pH} 5,8$ réduit l'activité de la protéase de $P$. camemberti à $50 \%$ de l'activité initiale. A pH 3 ou 6, l'enzyme est presque totalement inactivée. La température optimale d'action de l'enzyme de $P$. roqueforti est $50^{\circ} \mathrm{C}$ et elle est indépendante du substrat. Celle de la protéase acide de $P$. camemberti est proche de $45^{\circ} \mathrm{C}$. La stabilité thermique des deux enzymes est faible. A pH 4,0 et à $60{ }^{\circ} \mathrm{C}$ par exemple, la protéase de $P$. camemberti perd $90 \%$ de son activité après $13 \mathrm{mn}$.

Les aspartyl protéases des deux moisissures coagulent le lait. Toutefois, elles présentent un rapport activité coagulante/activité protéolytique nettement plus faible que celui de la chymosine et leur emploi comme substituts de la présure ne peut être envisagé.

Les deux enzymes activent le trypsinogène de bouf comme le font de nombreuses aspartyl protéases fongiques. Des travaux effectués à l'aide de peptides de synthèse révèlent que les liaisons de type Lys-X sont rapidement hydrolysées par cette catégorie d'enzymes et ils suggèrent que l'activation du trypsinogène se produit par la coupure d'une liaison Lys-Ile ainsi que le fait l'urokinase (MoRIHARA et OKA, 1973).

Les agents chélatants, les réactifs des enzymes à groupe SH et les composés actifs sur les sérine-protéases n'ont aucun effet sur les deux enzymes. En revanche, les réactifs classiques des protéases acides, le DAN (diazoacétyl DL norleucine méthylester) et l'EPNP (1,2-époxy-3-p-nitrophénoxy propane) les inactivent rapidement. Chacun de ces réactifs estérifie l'un des deux résidus aspartyle impliqués dans le mécanisme catalytique, le DAN se fixant sur le résidu protoné, l'EPNP sur le résidu sous forme dissociée. Dans le cas des enzymes de $P$. roqueforti et $P$. camemberti, il a été observé qu'une seule molécule de DAN et une seule molécule d'EPNP réagissent par molécule d'enzyme. Les protéases des deux Penicillium sont également inhibées par la butanedione, mais seulement à la lumière, l'inactivation étant due à une réaction photochimique avec certains résidus tyrosyle et tryptophanyle (GRIPON et HoFMANN, 1981). Une inhibition comparable est observée avec les protéases gastriques, telles que la pepsine ou la chymosine.

La comparaison des séquences $\mathrm{N}$-terminales de différentes protéases acides (pénicillopepsine, pepsine de porc, pepsine bovine, chymosine, gastricine) avec l'aspartyl protéase de $P$. roqueforti montre une homologie certaine entre les chaînes peptidiques (Gripon et al., 1977 b). En effet, les résidus 31 à 35 de toutes les enzymes sont identiques et cette région contient l'un des résidus aspartyle (Asp.2) impliqué dans le site actif. La séquence primaire complète des autres protéases acides fongiques (enzymes de $P$. janthinellum, Endothia parasitica et Mucor miehei) confirme l'homologie de ce groupe d'enzymes avec les protéases gastriques (chymosine et pepsine A). Il est généralement admis que les aspartyl 

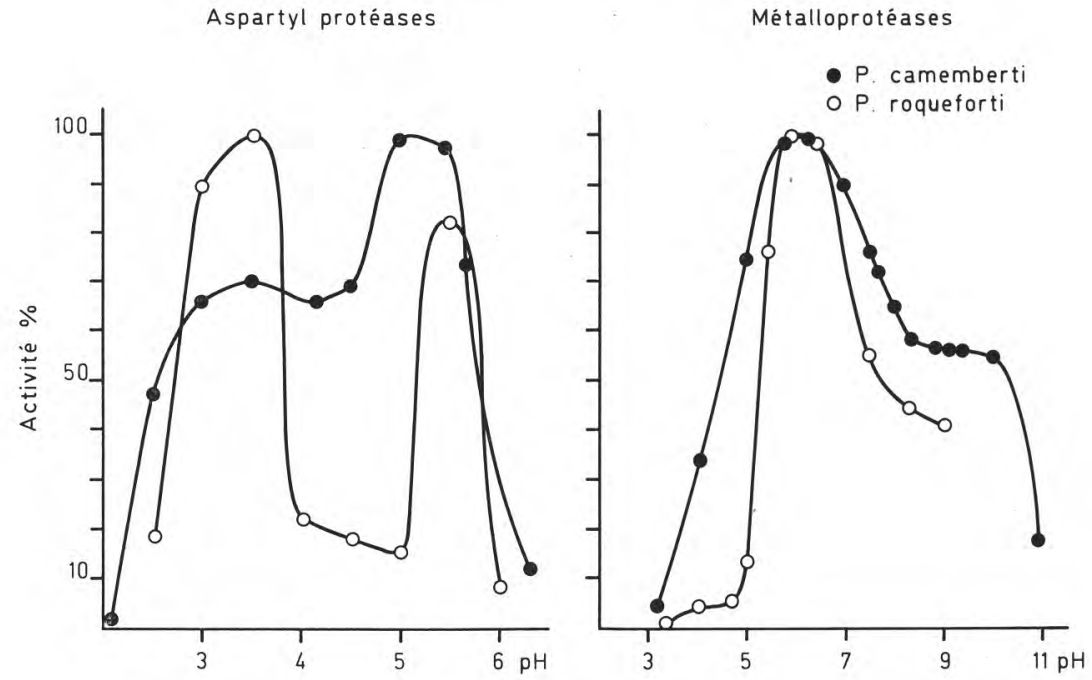

Fig. 2

Influence $d u$ pH sur l'activité des endopeptidases de $\mathrm{P}$. camemberti et $\mathrm{P}$. roqueforti (substrat caséine).

Influence of $\mathrm{pH}$ on the activity of endopeptidases of $\mathrm{P}$. camemberti and P. roqueforti (substrate casein).

TABLEAU II

Propriétés comparées des endopeptidases de $\mathrm{P}$. roqueforti et $\mathrm{P}$. camemberti Comparison of the properties of endopeptidases from $\mathrm{P}$. roqueforti and $\mathrm{P}$. camemberti

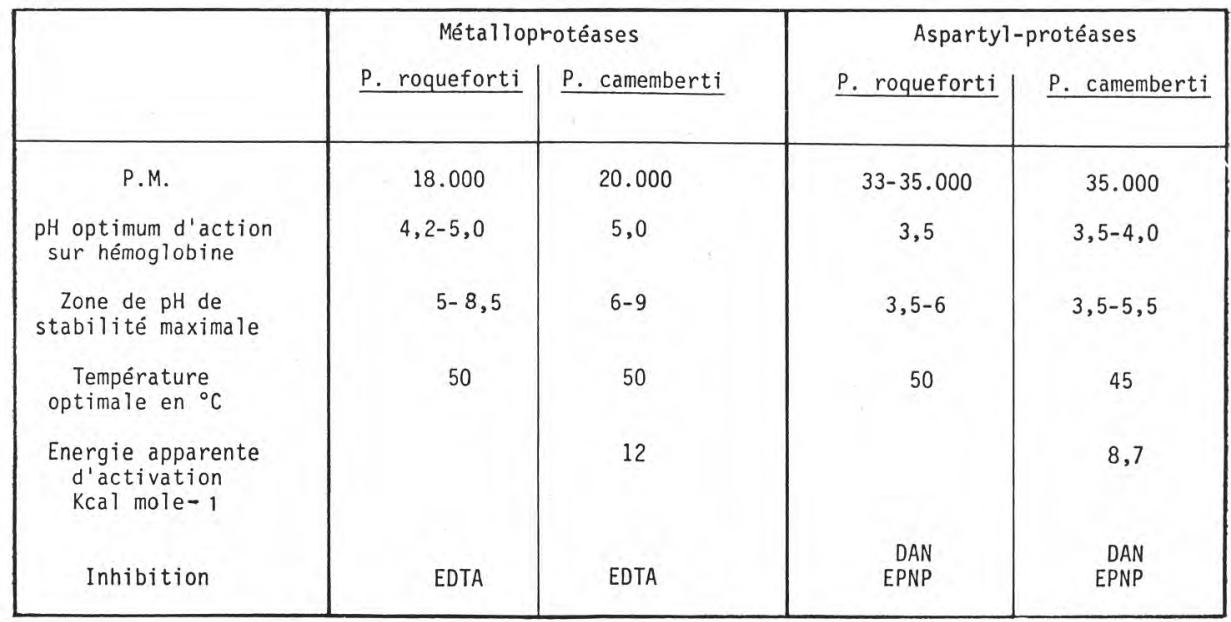


protéases gastriques et fongiques ont un ancêtre commun et résultent d'une évolution divergente.

Les systèmes protéolytiques liés au mycélium n'ont pas fait l'objet d'études aussi approfondies que ceux qui sont libérés dans le milieu de culture ; ils apparaissent cependant comporter également des aspartyl protéases. PAQUET et GRIPON (1980) ont mis en évidence, dans cinq souches de $P$. roqueforti, la présence de protéases acides présentant des poids moléculaires de 34000 à 44000 . Ces valeurs relativement dispersées peuvent s'expliquer par une glycosylation éventuelle de certaines molécules ainsi qu'il a été déjà observé sur d'autres protéases acides d'origine fongique (MOLDER et al., 1974). L'activité de la protéase acide mycélienne de $P$. camemberti s'identifie à celle de l'aspartyl protéase exocellulaire (Auberger et al., données non publiées).

\section{B. Les métalloprotéases}

Cultivés en milieu tamponné à $\mathrm{pH}$ proche de la neutralité, $P$. roqueforti et $P$. camemberti produisent chacun une métalloprotéase exocellulaire (GRIPON et Hermier, 1974 ; Lenorr et Auberger, 1977 a et b). Les deux enzymes ont des propriétés très voisines (tabl. II). Leur poids moléculaire est proche de 20000. Leur température optimale d'action est de $50^{\circ} \mathrm{C}$ et leur $\mathrm{pH}$ optimal est de 5,5-6,0 sur caséine (fig. 2), c'est-à-dire sensiblement inférieur à celui de la plupart des métalloprotéases microbiennes qui est généralement proche de 7. Les deux enzymes manifestent une activité encore importante à $\mathrm{pH} 8,5-9,0$ et leur zone de stabilité en fonction du $\mathrm{pH}$ est relativement large. Elles présentent une thermosensibilité différente; la protéase de $P$. roqueforti révèle un maximum d'instabilité à $65^{\circ} \mathrm{C}$ et elle conserve $25 \%$ d'activité résiduelle après un maintien de $20 \mathrm{mn}$ à $100^{\circ} \mathrm{C}$ en tampon à $\mathrm{pH} 6,0$. L'enzyme de $P$. camemberti est beaucoup moins stable ; elle perd $90 \%$ de son activité après un chauffage de $40 \mathrm{mn}$ à $55^{\circ} \mathrm{C}$.

L'inactivation par l'EDTA, caractéristique des métalloprotéases, est très nette pour les deux enzymes. Dans le cas de la protéase de $P$. camemberti, il n'est pas nécessaire de faire agir l'agent chélatant à $\mathrm{pH}$ faible pour obtenir une inhibition totale. En revanche, pour l'enzyme de $P$. roqueforti, l'inhibition n'est complète que pour des valeurs de $\mathrm{pH}$ inférieurs à 5,0 . Certains cations divalents réactivent les enzymes inhibées par action de l'EDTA; le plus efficace est dans les deux cas le cobalt, ce qui les distingue d'autres métalloprotéases pour lesquelles le zinc est le métal assurant la plus forte réactivation.

Le cobalt active également les enzymes non inhibées, mais cette activation est très faible pour l'enzyme de $P$. camemberti alors qu'elle est particulièrement importante pour la protéase de $P$. roqueforti. En effet, à une concentration en cobalt de $10^{-2} \mathrm{M}$ l'activité enzymatique représente $200 \%$ de l'activité en absence de métal et l'activation est encore décelable à une concentration en $\mathrm{Co}^{++}$de $10^{-6} \mathrm{M}$.

Les métalloprotéases de $P$. camemberti et de $P$. roqueforti contiennent respectivement 0,83 et 0,70 atome de zinc, 1,8 et 0,14 atome de calcium par molécule de protéines. Les apoenzymes conservent les teneurs en calcium originelles mais elles ne contiennent pratiquement plus de zinc, ce qui indique la présence nécessaire de ce métal pour la manifestation de l'activité catalytique (GRIPON et al., 1980). 
Les protéases des deux Penicillium exercent une action comparable sur la chaîne $B$ de l'insuline. Après un temps relativement court $(15 \mathrm{mn})$ les deux enzymes libèrent quatre peptides Phe1-Ala14, Phe1-Tyr16, Leu15-Tyr16 et Leu17$\mathrm{Ala}_{30}$ correspondant à l'hydrolyse des liaisons $\mathrm{Ala}_{14}-\mathrm{Leu}_{15}$ et $\mathrm{Tyr}_{16}-\mathrm{Leu}_{17}$. Après hydrolyse prolongée ( 8 heures), il y a libération d'un grand nombre de peptides indiquant que les deux protéases ont une faible spécificité. Aucune règle précise ne peut être définie pour cette spécificité, mais elle est différente de celle des métalloprotéases «neutres » (type thermolysine), lesquelles ont une affinité particulière pour les liaisons peptidiques impliquant un résidu hydrophobe engagé par son groupement aminé. Il semble qu'une longueur de chaîne minimale soit nécessaire pour que les deux enzymes soient actives, en effet les petits substrats tels que les dipeptides disubstitués ne sont pas dégradés.

Les protéines basiques (protamine, histone) sont hydrolysées avec un meilleur rendement par les métalloprotéases de $P$. roqueforti et de $P$. camemberti que la caséine, laquelle est attaquée à une vitesse beaucoup plus grande que l'hémoglobine ; le collagène et la kératine ne sont pas dégradés.

Les deux enzymes ont des compositions en acides aminés semblables; elles sont dépourvues de tryptophane et de méthionine, contiennent peu d'isoleucine et de phénylalanine, mais présentent une très forte proportion d'alanine.

La comparaison des séquences $\mathrm{N}$ terminales des deux protéines confirme bien cette analogie, puisque, parmi les 22 premiers résidus, les seules différences observées sont relatives aux positions 7 et 8 qui sont pour l'enzyme de $P$. roqueforti Asn et Ala et pour celle de P. camemberti Asp et Ser.

Il apparaît donc que les métalloprotéases de $P$. roqueforti et $P$. camemberti ont des propriétés très voisines et peuvent être considérées comme des enzymes homologues. En revanche, par leur spécificité, leur pH optimal d'action et leur poids moléculaire, elles se distinguent nettement des autres métalloprotéases microbiennes, en particulier des métalloprotéases «neutres», telles la thermolysine. Elles appartiennent au sous-groupe des métalloprotéases « acides » auquel s'apparentent également les enzymes synthétisées par Aspergillus sojae (SEKINE, 1972 ) et $A$. oryzae (NAKADAI et al., 1973). Cette différence est d'ailleurs confirmée par le fait que le phosphoramidon, un inhibiteur des métalloprotéases neutres, est sur elles sans action.

Des activités protéolytiques comparables à celles des métalloprotéases exocellulaires ont été mises en évidence dans le mycélium des deux moisissures (PAQUet et Gripon, 1980 ; Auberger et al., données non publiées). La caractérisation de cette activité dans le cas de $P$. camemberti a montré que l'enzyme responsable s'identifie à celle qui est libérée dans le milieu de culture.

\section{Les carboxypeptidases}

$P$. camemberti et $P$, roqueforti possèdent des carboxypeptidases actives à $\mathrm{pH}$ acide et neutre (tabl. III).

La carboxypeptidase acide mise en évidence pour $P$. roqueforti appartient au groupe des enzymes à sérine, qui ont, dans leur site actif, un résidu séryl sensible au DFP. L'enzyme exocellulaire a un $\mathrm{pH}$ optimal d'action proche de 3,5 sur le substrat carbobenzoxy-glu-tyr (Z-glu-tyr), un poids moléculaire de 110000 , une stabilité maximale entre $\mathrm{pH} 5,0$ et 5,5, l'inactivation étant rapide aux $\mathrm{pH}$ supérieurs à 6,0 . La température optimale d'action est de $40^{\circ} \mathrm{C}$. L'enzyme est 


\section{TABleau III}

Propriétés des exopeptidases de $\mathrm{P}$. roqueforti et $\mathrm{P}$. camemberti

Properties of exopeptidases of $\mathrm{P}$. roqueforti and $\mathrm{P}$. camemberti

\begin{tabular}{|c|c|c|c|c|c|c|c|c|}
\hline & \multicolumn{4}{|c|}{ Carboxypeptidases } & \multicolumn{4}{|c|}{ Aminopeptidases } \\
\hline & \multicolumn{2}{|c|}{ P. roqueforti } & \multicolumn{2}{|c|}{ P. camemberti } & \multicolumn{2}{|c|}{ P. roqueforti } & \multicolumn{2}{|c|}{ P. camemberti } \\
\hline & exoc. & endoc. & exoc. & endoc. & exoc. & endoc. & exoc. & $\overline{\text { endoc }}$ \\
\hline P.M. & 110.000 & 150.000 & 120.000 & - & 35.000 & 55.000 & 35.000 & - \\
\hline pH optimum & 3,5 & 3,6 & $3,0-3,5$ & $6-6,5$ & $7,5-8,0$ & 7,5 & $8,0-8,5$ & 8,5 \\
\hline $\begin{array}{l}\text { Zone de pH de } \\
\text { stabilité maximale }\end{array}$ & $5,0-5,5$ & $2-6$ & $4-5$ & $5,5-8,0$ & $6,0-7,0$ & & $6,0-8,0$ & $6,0-8,0$ \\
\hline
\end{tabular}

relativement thermo-sensible et devient instable aux températures supérieures à $42{ }^{\circ} \mathrm{C}$ (Gripon, 1977 a).

La spécificité d'action de l'enzyme est large; sur le glucagon elle libère en effet les acides aminés hydrophobes, acides ou basiques. En revanche, elle ne coupe que très lentement la liaison $\mathrm{PrO}_{28}-\mathrm{Lys}_{29}$ de la chaîne $\mathrm{B}$ de l'insuline contrairement à d'autres carboxypeptidases à sérine d'origine microbienne (HAYASHI et al., 1973).

La carboxypeptidase liée au mycélium, isolée et caractérisée par ICHIsHImA et al. (1978), a des propriétés comparables : un $\mathrm{pH}$ optimal de 3,6 , un poids moléculaire proche de 150000 , une bonne stabilité à $30^{\circ} \mathrm{C}$ entre $\mathrm{pH} 2$ et 6 , une inactivation partielle après maintien $10 \mathrm{mn}$ à $50^{\circ} \mathrm{C}$, l'aptitude de libérer les acides aminés neutres ou basiques, ainsi que la proline C-terminale de l'angiotensine.

L'activité carboxypeptidasique exocellulaire de $P$. camemberti s'identifie également à une carboxypeptidase acide. Elle est maximale à $\mathrm{pH} 3,5$ sur le dérivé Z-Glu-Tyr et elle devient nulle à $\mathrm{pH}$ inférieur à 2 ou supérieur à 6 . Sa stabilité est maximale dans l'intervalle de $\mathrm{pH} \mathrm{4-5}$ et son poids moléculaire est voisin de 120000 (Auberger et al., 1985). L'enzyme isolée par Ahiko et al. (1981 a) a un pH optimal de 3,0 et un poids moléculaire de 126000 , son activité est favorisée par la présence d'un acide aminé aromatique en position pénultienne. Elle libère particulièrement bien les acides aminés hydrophobes et elle a la propriété de diminuer l'amertume des hydrolysats de caséines ou de protéines de soja (Аніко et al., 1981 b).

Les connaissances sur les carboxypeptidases neutres ou alcalines des deux moisissures sont plus fragmentaires. Leur présence dans le milieu de culture ou dans le mycélium a été observée avec $P$. roqueforti (GRIPON et DEBEST, 1976; PAQUet et GRIPON, 1980). Pour P. camemberti, ces enzymes resteraient liées au mycélium. L'activité carboxypeptidasique mycélienne de cette moisissure présente un pH optimal d'action de 6,0-6,5 sur Z-gly-val et de 5,0 sur Z-glu-tyr, mais avec une activité relative de 0,5 par rapport au précédent substrat, une stabilité maximale entre $\mathrm{pH} 5,5$ et 8,0 . La présence d'au moins deux composants de spécificité et de pH optimaux différents a été établie (AuBERGER et al., 1985). 


\section{Les aminopeptidases}

Les deux moisissures synthétisent des aminopeptidases alcalines qui peuvent être libérées dans le milieu de culture ou rester liées au mycélium (tabl. III).

L'aminopeptidase exocellulaire de $P$. roqueforti est inhibée par l'EDTA; il s'agit, comme dans le cas d'autres aminopeptidases microbiennes, d'une métalloenzyme (GRIPON, 1977 b). L'inhibition par le PHMB (p-hydroxymercuribenzoate) suivie d'une réactivation par le dithiothreitol suggère qu'un ou plusieurs groupes SH sont nécessaires à la manifestation de l'activité catalytique. L'enzyme a un pH optimum d'action de 8,0 sur la leucine p-nitroanilide (LNA) et de 7,5 sur Met-LeuGly. Elle est formée d'une chaîne peptidique de poids moléculaire proche de 35000 . L'enzyme est stable entre $\mathrm{pH}$ 6,0 et 7,0 mais elle perd rapidement son activité au-dessus de $\mathrm{pH} 8$. Les températures supérieures à $40{ }^{\circ} \mathrm{C}$ la dénaturent rapidement. L'étude de la spécificité sur des peptides de synthèse révèle que seuls les acides aminés apolaires (Leu, Ala, Met) sont rapidement libérés ; la présence d'une glycine en position pénultiène réduit considérablement le taux d'hydrolyse.

$P$. roqueforti possède également deux aminopeptidases liées au mycélium de poids moléculaire proche de 55000 , mais qui diffèrent par leur spécificté (PAQUET et GRIPON, 1980). L'une hydrolyse la LNA et les dérivés $\beta$-naphtalamide $(\beta N A)$ de Leu, Ala, Arg et Gly ; l'autre attaque les dérivés $\beta$ NA de Leu, Ala et Asp mais est sans action sur la LNA. L'activité de ces enzymes est également inhibée par l'EDTA et le PHMB.

L'activité aminopeptidasique exocellulaire de $P$, camemberti est optimale à $\mathrm{pH} 8-8,5$ sur LNA et sa stabilité est maximale de $\mathrm{pH} 6$ à 8 (AUBERgER et al., 1982). Elle paraît être formée de plusieurs composants. Deux bandes d'activité sont présentes sur les diagrammes électrophorétiques de toutes les souches éprouvées. $\mathrm{La}$ bande majeure est active sur les dérivés $\beta \mathrm{NA}$ de $\mathrm{Arg}$, Leu, Met, Lys et Ala; la bande secondaire l'est seulement sur les quatre premiers dérivés. Une troisième bande se manifeste dans les diagrammes de certaines souches et son activité, qui est faible, porte sur les dérivés $\beta$ NA de Asp et Leu.

L'activité aminopeptidasique liée au mycélium présente une certaine similitude avec la précédente. Elle a des caractéristiques d'action comparables sur LNA et les diagrammes électrophorétiques révèlent la présence de deux bandes d'activité, la principale s'identifiant à la bande majeure de l'activité exocellulaire, celle de plus faible intensité à la troisième bande mise en évidence dans les filtrats de cultures de certaines souches.

\section{E. Production des enzymes}

La production d'enzymes protéolytiques par les moisissures dépend d'un certain nombre de paramètres et en premier lieu de la composition du milieu de culture. Le milieu de base assez généralement utilisé pour ces études a été celui de Czapek avec, cependant, certaines modifications concernant notamment les sources d'azote ou de carbone.

Ainsi, avec $P$. camemberti, la croissance du mycélium et la production d'enzymes exocellulaires actives sur caséine à $\mathrm{pH} 6$ sont très nettement favorisées par le remplacement de l'azote nitrique par une peptone trypsique de caséine 
(LenOIr et Choisy, 1971 ; LenOIr et al., 1973). La source de carbone assurant la production maximale d'enzymes est le glucose, les teneurs optimales se situant de 20 à $40 \mathrm{~g}$ par litre. L'alimentation minérale n'est pas non plus sans influence. La présence de chlorure de calcium à des concentrations de 0,005 ou $0,01 \mathrm{M}$ provoque une diminution sensible de la production; cet effet dépressif est évité si la concentration en $\mathrm{CaCl}_{2}$ est abaissée à $10^{-5} \mathrm{M}$. Le magnésium est indispensable à la production de protéases, bien qu'en son absence la croissance reste proche de la normale. Les sulfates ne semblent avoir aucun effet, mais d'autres formes de soufre minéral, sulfite ou hyposulfite, exercent une influence favorable. Les phosphates sont nécessaires à la croissance et à la synthèse des enzymes et l'emploi d'un tampon phosphate à une concentration de 0,05 à $0,1 \mathrm{M}$ permet de limiter l'évolution du $\mathrm{pH}$ des cultures, ce qui se traduit par un accroissement notable de production de protéases. La présence d'oligo-éléments minéraux en quantité appropriée est également nécessaire pour assurer une sécrétion maximale d'enzymes. En revanche, l'apport de facteurs de croissance par addition d'extrait de levure ou d'extrait de malt est sans effet ou n'a qu'un effet très limité. Parmi les facteurs de production autres que la composition du milieu de culture, la température, le $\mathrm{pH}$ et l'agitation exercent une influence marquée. Les conditions optimales correspondent à une température de culture de $20-22^{\circ} \mathrm{C}$ et un pH compris entre 5,5 et 6,5 , en milieu non agité mais avec une répartition en fioles assurant un large contact avec l'air. Dans ces conditions, le développement du mycélium et la sécrétion d'enzymes exocellulaires s'amorcent vers le $4^{\mathrm{e}}$ jour ; loptimum de production est atteint en 12 jours. En culture agitée, à la température de $25^{\circ} \mathrm{C}$, le niveau de production maximum est atteint en 6 à 8 jours mais il est moins élevé qu'en milieu non agité. Il est à noter qu'avec $P$. camemberti la vitesse de production d'enzymes protéolytiques est relativement faible, et qu'en fermenteur il n'y a pas excrétion d'enzymes.

$P$. roqueforti, comme de nombreux autres champignons, n'a pas du tout le même comportement. Ses cultures en milieu agité évoluent beaucoup plus rapidement (GRIPON et BERGERE, 1972 ; GRIPON, 1978). En fermenteur et en milieu tamponné à $\mathrm{pH} 6,0$, la production de protéase (mesurée à $\mathrm{pH} 6,0$ ) est détectable dès $36 \mathrm{~h}$ de culture et elle passe par un maximum après environ $60 \mathrm{~h}$.

Compte tenu de la complexité du système protéolytique des deux espèces, les conditions de culture peuvent influer différemment sur la vitesse et le niveau de production des divers composants. Ainsi le $\mathrm{pH}$ du milieu joue un rôle capital dans la nature des enzymes produites. Dans le cas de $P$. roquefort $i$, un milieu tamponné à $\mathrm{pH}$ acide (voisin de 4) aboutit à la production d'aspartyl protéase en forte quantité et de carboxypeptidase acide en quantité beaucoup plus faible. En milieu tamponné à $\mathrm{pH}$ 6,0, le système exocellulaire est plus complet puisque, outre les deux enzymes précédentes, la métalloprotéase, l'aminopeptidase et une activité carboxypeptidasique alcaline sont produites conjointement. Les proportions d'enzymes présentes diffèrent sensiblement suivant le $\mathrm{pH}$ du milieu ; un $\mathrm{pH}$ acide favorise nettement la synthèse de l'aspartyl protéase, un $\mathrm{pH}$ proche de la neutralité aboutit à une production appréciable de métalloprotéase.

Les mêmes observations ont été faites sur $P$. camemberti (LENOrr et AUBERGER, 1977 a ; LENOIR et al., 1979). Dans les cultures à pH 6,5, la métalloprotéase (MP) représente l'endopeptidase dominante, le rapport des activités MP/AP est voisin de 2 ; en cultures à $\mathrm{pH} 4$, il y a essentiellement production de l'aspartyl protéase (AP), la proportion de MP étant pratiquement négligeable. 
L'aptitude de $P$. camemberti à la production d'enzymes actives sur caséine à $\mathrm{pH} 6,0$ a été déterminée sur une collection d'une centaine de souches de diverses origines (LENOIR et CHOISY, 1971). Les résultats obtenus sont relativement groupés; l'activité exocellulaire varie de 210 à 450 unités, celle liée au mycélium de 60 à 230 . L'espèce apparaît donc présenter, au plan de son aptitude à la production d'enzymes protéolytiques, une assez grande homogénéité. Toutefois, la répartition des souches en fonction de leur activité exocellulaire fait apparaître l'existence de deux sous-groupes, le plus actif rassemblant la presque totalité des souches d'origine Neufchâtel. Une observation analogue faite sur l'activité lipolytique et sur l'aptitude à la dégradation oxydative des acides gras (cf. chap. 5) conforte l'hypothèse selon laquelle les souches Neufchâtel représentent bien, au sein de l'espèce, un sous-ensemble original. Il n'a pas été relevé de corrélation entre les activités exo et endocellulaires, ni entre les niveaux de production d'enzymes et les poids du mycélium. En revanche, une corrélation positive assez étroite $(\mathrm{r}=0,86)$ a été observée entre les activités protéolytiques et lipolytiques pour l'ensemble des souches de la collection (LAMBERET et LeNoIr, 1972).

Une étude des niveaux de production des diverses enzymes protéolytiques de $P$. camemberti, conduite sur 16 souches (AUBERGER et al., 1985) a montré que le potentiel de production de chaque enzyme, au $\mathrm{pH}$ de culture correspondant à l'optimum, varie relativement peu d'une souche à l'autre (fig. 3). Dans le cas de la métalloprotéase et des activités aminopeptidasique et carboxypeptidasique acide l'amplitude de variation se situe dans un intervalle voisin de 1 à 3 ; il est encore plus faible, proche de 1 à 1,5 , pour ce qui concerne l'aspartyl protéase et l'activité carboxypeptidasique neutre. Aucune corrélation n'a été observée entre les niveaux de production des différentes enzymes.

\section{Action in vitro}

\section{F. Action des enzymes protéolytiques}

L'action des endopeptidases sur les différents composants de la caséine a été déterminée. L'aspartyl protéase de $P$. camemberti agit sur les caséines $\alpha_{81}, \beta$ et $\mathrm{K}$ mais le $\mathrm{pH}$ optimum varie selon la nature du substrat (LenOIR et AUBERger, 1982 b). Il est proche de 3,5 avec la caséine $\mathrm{K}$, mais se situe vers 5,5 pour les caséines $\alpha_{\mathrm{s} 1}$ et $\beta$. A pH 5, la caséine $\alpha_{\mathrm{s} 1}$ est plus fortement dégradée que les composants $\beta$ et $\mathrm{K}$, les degrés relatifs d'hydrolyse étant respectivement $1,0,7,0,6$.

L'hydrolyse des caséines par les aspartyl protéases de $P$. roqueforti et $P$. camemberti a été étudiée et comparée par des techniques de focalisation isoélectrique et d'électrophorèse bidimensionnelle (TrIEU-CUOT et GRIPON, 1981 ; Trieu-Cuot et al., 1982 b). Les deux enzymes ont une action présentant une grande analogie. Elles hydrolysent la caséine $\beta$ en formant 5 produits de dégradation désignés $\beta$ ap1 à $\beta$ ap 5 . Ces peptides apparaissent selon la même cinétique et ils possèdent des points isoélectriques et des poids moléculaires apparents identiques. Cette similitude a été confirmée par identification des peptides isolés à partir des hydrolysats de caséine $\beta$. Ils correspondent à la coupure de trois liaisons $\mathrm{Lys}_{29}-\mathrm{Ile}_{30}, \mathrm{Lys}_{99}-\mathrm{Glu}_{100}$ et $\mathrm{Lys}_{97}-\mathrm{Val}_{98} ; \beta \alpha \mathrm{p}_{1}, \beta \mathrm{ap}_{2}, \quad \beta \mathrm{ap}_{3}$ et $\beta a p_{5}$ représentant respectivement des fragments 98-209, 100-209, 30-209 et $1-97 / 99, \beta \mathrm{ap}_{4}$ étant probablement le peptide 1-29. Sur la caséine $\alpha_{\mathrm{s} 1}$, les deux aspartyl protéases exercent également une action analogue. Après deux heures de 


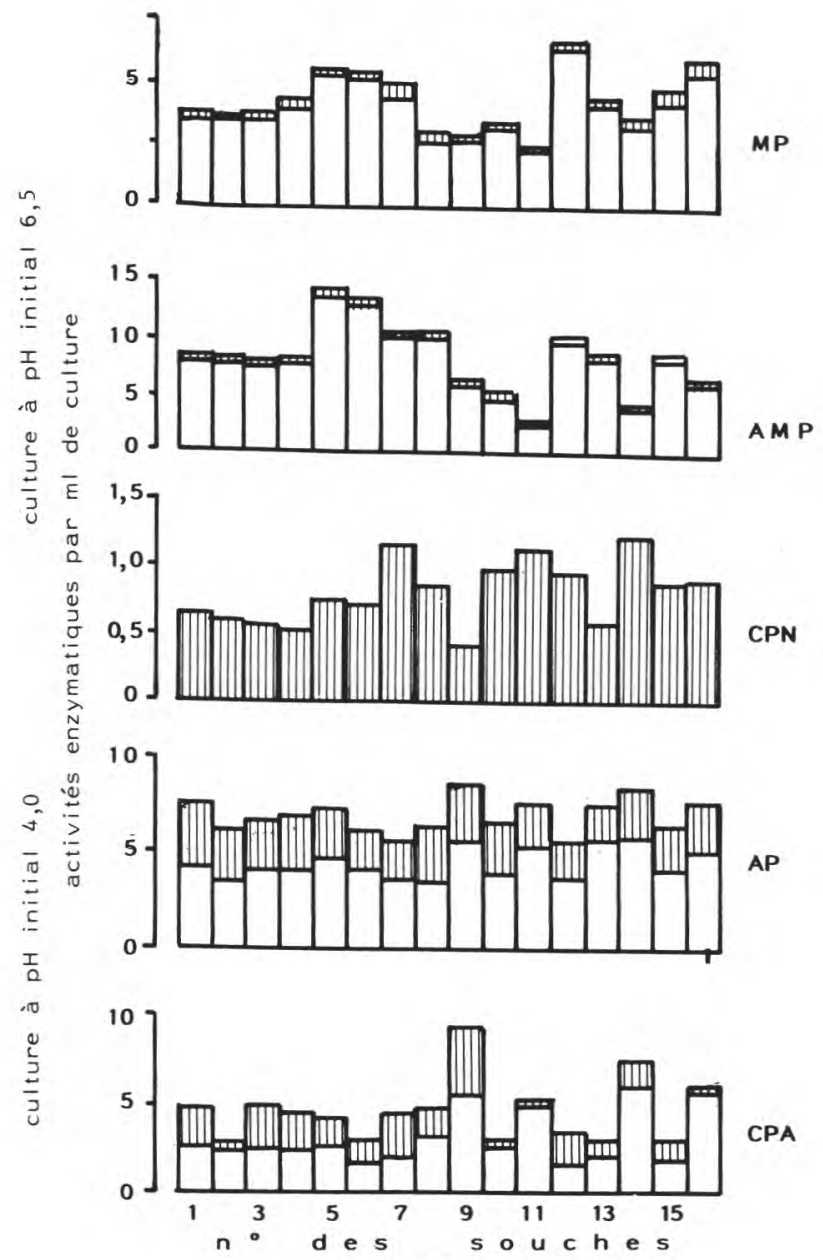

Fig. 3

Niveaux de production des enzymes protéolytiques de P. camemberti. Variations selon les souches.

$$
\begin{aligned}
& M P=\text { métalloprotéase } \\
& A P=\text { aspartylprotéase } \\
& C P N=\text { carboxypeptidase neutre } \\
& C P A=\text { carboxypeptidase acide } \\
& A M P=\text { aminopeptidase }
\end{aligned}
$$$$
\text { micromoles de tyrosine }-h^{-1}
$$$$
\text { micromoles de norleucine }-h^{-1}
$$$$
\text { micromoles de leucine }-h^{-1}
$$

Production level of proteolytic enzymes of P. camemberti. Variations among the strains.

孟 activité présente dans le mycélium.

activité présente dans le filtrat de culture.

réaction, les diagrammes de focalisation révèlent la présence dans chaque hydrolysat de six bandes majeures qui correspondent à la coupure préférentielle de quatre liaisons. Toutefois, il existe des différences dans les cinétiques d'hydrolyse 
et l'une des liaisons est coupée plus rapidement par l'enzyme de $P$. roqueforti que par celle de $P$. camemberti.

La métalloprotéase de $P$. camemberti attaque les trois caséines $\alpha_{81}, \beta$ et $\mathrm{K}$ avec un même $\mathrm{pH}$ optimum d'action $(6,0)$. La caséine $\alpha_{\mathrm{g} 1}$ est plus fortement dégradée que les composants $\beta$ et $\mathrm{K}$, les degrés relatifs d'hydrolyse à $\mathrm{pH} 6$ sont respectivement 1, 0,4, 0,6 (LeNOIR et AUBERger, 1982 b).

L'étude électrophorétique de l'action des métalloprotéases des deux moisissures sur les caséines $\alpha_{s 1}$ et $\beta$ révèle l'apparition de 8 et 11 bandes majeures et elle montre que les deux protéases ont sur ces substrats des spécificités proches mais que les vitesses de coupure de certaines liaisons peuvent varier beaucoup d'une enzyme à l'autre (Trieu-Cuot et al., 1982 a). L'isolement par chromatographie des peptides d'un hydrolysat de caséine $\beta$ a permis d'identifier trois liaisons sensibles à la métalloprotéase de $P$. camemberti $\left(\mathrm{Lys}_{28}-\mathrm{Lys}_{29}, \mathrm{Pro}_{90}-\mathrm{Glu}_{91}\right.$ et $\left.\mathrm{Glu}_{100}-\mathrm{Ala}_{101}\right)$.

Il apparaît finalement une grande analogie d'action entre les enzymes des deux espèces, cette analogie étant toutefois plus marquée pour les aspartyl protéases que pour les métalloprotéases.

\section{Action in situ}

La protéolyse dans les fromages à croûte fleurie ou à pâte persillée est particulièrement importante. En fin d'affinage, la teneur en azote soluble d'un camembert atteint $35 \%$ de l'azote total (LENOIR, 1962), celle des pâtes persillées est voisine de $50 \%$ (Devoyod et al., 1968). En outre, dans ces dernières, les acides aminés libres sont présents en proportion élevée (jusqu'à $10 \%$ de l'azote total) et

(A)

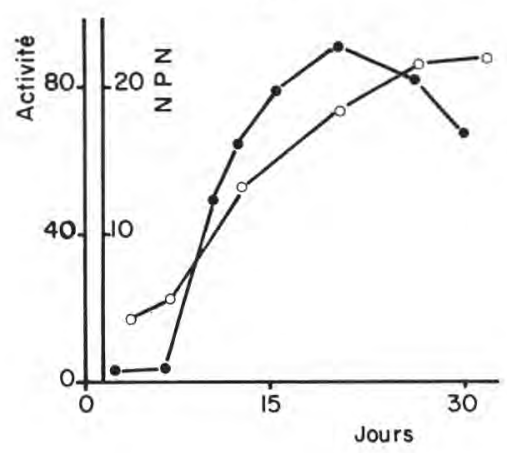

(B)

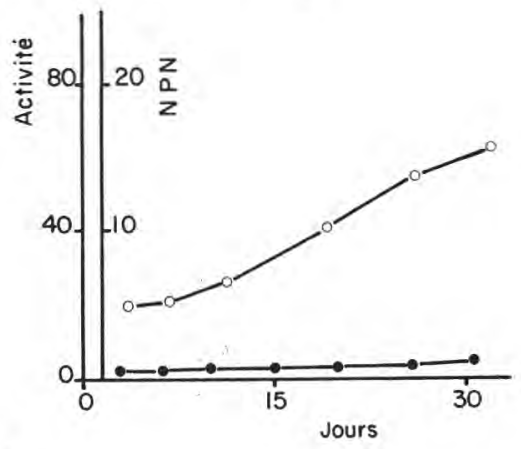

Fig. 4

Evolutions comparées de l'activité protéolytique et des teneurs en azote non protéique du fromage de camembert au cours de l'affinage A-surface, B-partie interne (LENoIR, 1970).

- Activité protéolytique exprimée en $\mu \mathrm{g}$ de tyrosine libérée par $m l$ de préparation et par heure.

○- 0 Teneurs en azote non protéique en \% de l'azote total.

Development of proteolytic activity and non protein nitrogen of camembert cheese during ripening A-surface, B-center (LeNOIR, 1970). 
dans le camembert la somme acides aminés libres-ammoniac représente plus de $1 / 3$ de l'azote soluble.

La part des moisissures dans cette dégradation des caséines est particulièrement déterminante. Ainsi, dans le camembert, les différences dans l'évolution des matières azotées des parties externe et interne (LENOIR, 1962) mettent clairement en évidence l'action prédominante du Penicillium (fig. 4). Cette dernière se retrouve encore dans le parallélisme observé entre le développement du mycélium et l'évolution de l'activité protéolytique à la surface du fromage, alors qu'au cour de la pâte l'activité reste très faible (LENOIR, 1970).

Cette action a été confirmée par les études sur caillés modèles à flore contrôlée. La technique des caillés aseptiques, en isolant le rôle d'une souche microbienne ou d'une enzyme, a en effet permis de mieux définir l'action des Penicillium au cours de l'affinage (LE BARs et al., 1975). Dans les caillés où agissent seules la présure et les protéases natives du lait, l'azote soluble augmente régulièrement et atteint $18 \%$ après 48 jours de maturation. Cette fraction est essentiellement constituée de peptides; elle ne contient pas ou ne contient que très peu d'acides aminés. Dans le caillé ensemencé avec une souche de $P$. camemberti ou de $P$. roqueforti, la protéolyse est beaucoup plus intense. En fin d'affinage, les teneurs en azote soluble à $\mathrm{pH} 4,6$, en azote non protéique et en azote soluble dans l'acide phosphotungstique sont respectivement voisines de 50, 30 et $10 \%$ de l'azote total (DesmazeAud et al,, 1976). Ces valeurs indiquent une production importante de peptides de haut et bas poids moléculaires élevés ainsi que d'acides aminés libres et elles marquent bien le rôle majeur des Penicillium dans l'affinage des fromages concernés.

L'incorporation à des caillés aseptiques de l'aspartyl protéase de $P$. roqueforti ou de la métalloprotéase de $P$. camemberti entraîne la formation de peptides de poids moléculaire plus ou moins élevé mais non la libération d'acides aminés (GRIPON et al., 1977 a). En outre, les diagrammes électrophorétiques des caillés avec moisissure seule ou enzyme seule révèlent la présence de peptides de faible mobilité (issus de la caséine $\beta$ ) qui sont caractéristiques de ces enzymes. Ainsi la synthèse et l'action des enzymes des Penicillium au cours de l'affinage des fromages sont bien démontrées; les acides aminés libres résultent de l'action des exopeptidases, la large spécificité des carboxypeptidases à sérine devant leur permettre de libérer à la fois des acides aminés apolaires, acides ou basiques.

Les parts respectives des actions des endopeptidases sont plus difficiles à apprécier. La détermination de l'activité des deux enzymes de $P$. camemberti (métalloprotéase et aspartyl protéase) a été effectuée dans les parties superficielle et interne de camembert par incubation de suspension de fromages en présence de substrat protéique à $\mathrm{pH} 4,0 \mathrm{ou} \mathrm{pH} \mathrm{7,5}$ (LENOIr et Auberger, $1982 \mathrm{a}$ ). Il apparait que les deux enzymes sont produites en surface principalement entre le $6^{\mathrm{e}}$ et le $9^{e}$ jours d'affinage. Leur activité est maximale vers le $15^{\mathrm{e}}$ jour, elle décroît ensuite, mais lentement, indiquant ainsi que les deux protéases présentent une assez grande stabilité dans les conditions physico-chimiques de la zone externe des camemberts (fig. 5). L'évolution du pH dans la partie superficielle de la pâte ainsi que les caractéristiques propres des enzymes purifiées suggèrent que toutes deux agissent en début d'affinage mais qu'à partir du $16^{\mathrm{e}}-18^{\mathrm{e}}$ jour, le $\mathrm{pH}$ du fromage devient trop élevé pour permettre l'action de la protéase acide si bien qu'en fin d'affinage seule la métalloprotéase serait en mesure d'exercer son activité. Sur cette base, l'estimation du potentiel d'action des deux enzymes aux divers stades de l'affinage tend à attribuer un rôle dominant à la métalloprotéase. 


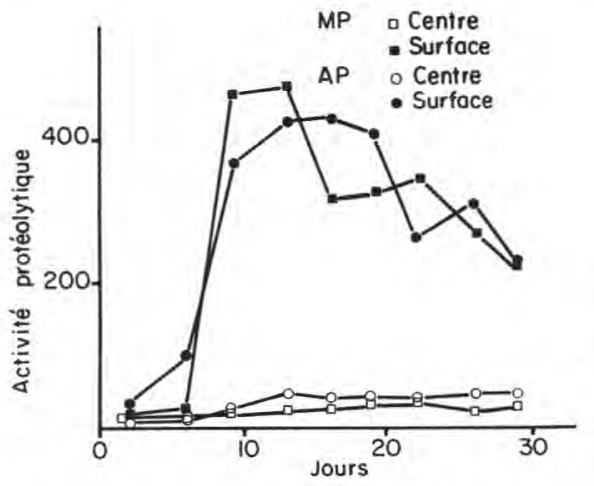

Fig. 5

Evolution des activités de la métalloprotéase $(M P)$ et de l'aspartyl protéase (AP) de $\mathrm{P}$. camemberti au cours de l'affinage du fromage de camembert (LENOIR et AUBERGER, 1982 b).

Activité protéolytique exprimée en $\mu \mathrm{g}$ de tyrosine par $\mathrm{ml}$ de préparation (détermination effectuée sur filtrat trichloracétique à $12 \%$ ).

Change in activity of the metalloproteinase (MP) and the acid proteinase (AP) of $\mathrm{P}$. camemberti during ripening of camembert cheese (LENOIR and AUBERGER, 1982 b).

Proteolytic activity expressed in $\mu \mathrm{g}$ tyrosine/ml preparation (assay on filtrate of $12 \%$ trichloracetic acid).

L'action des protéases de $P$. camemberti a pu également être suivie par la détection électrophorétique des peptides $\beta \mathrm{mp}_{1}, \beta \mathrm{mp}_{2}$ et $\beta \mathrm{ap}_{1}$, respectivement caractéristiques des activités de la métalloprotéase et de la protéase acide (TrieUCuOT et GRIPON, 1982 a et b). Dans les camemberts, il apparaît que l'activité de la première est détectable à partir du $7^{\mathrm{e}}$ jour d'affinage, c'est-à-dire immédiatement après le développement du Penicillium. L'intervention de la seconde l'est 3 jours plus tard. Le peptide $\beta a p_{1}$, présent à partir du $10^{\mathrm{e}}$ jour, s'intensifie ensuite au cours de l'affinage, ce qui suggère que l'aspartyl protéase reste active même en fin de maturation, malgré le $\mathrm{pH}$ élevé de la pâte fromagère. A l'inverse, les produits résultant de l'action de la métalloprotéase décroissent après 10 jours d'affinage. On ne peut cependant en conclure que cette enzyme n'intervient plus car ses produits de dégradation peuvent être eux-mêmes hydrolysés par les autres enzymes, notamment les exopeptidases du Penicillium.

L'étude électrophorétique des fromages à pâte persillée montre une grande similitude avec le mode de dégradation observé dans les camemberts. La protéolyse est, dans les deux types de fromage, qualitativement voisine et elle reflète bien l'homologie observée sur les systèmes protéolytiques des deux moisissures. L'hydrolyse est cependant plus poussée dans les pâtes persillées et l'action de la protéase acide est détectable aussitôt après le développement du Penicillium, en même temps que celle de la métalloprotéase, alors qu'un décalage a été constaté dans le cas du camembert.

\section{Lipolyse et enzymes lipolytiques}

\section{A. Nature des enzymes}

Fodor et CHARI (1949) ont fait état pour $P$. roqueforti de deux types d'activité lipasique sur la base de leur pH optimal d'action, 8,0-8,3 ou 6,5 , et de 
certaines différences dans la spécificité vis-à-vis des substrats. Par la suite, divers travaux ont confirmé la présence d'au moins deux enzymes sans qu'elles soient nettement séparées et sans que leurs caractéristiques soient bien décrites (e.g. MORRIS et JEZESKI, 1953 ; IMAMURA et KATAOKA, 1963 a et b, 1966 ; NiKI et al., 1966). Finalement une lipase alcaline a été caractérisée par EITENMILLER (1968) et l'activité acide par LoBYREVA et MARCHENKOva $(1980,1981)$ et LAMBERET et Menassa (1983 a).

Pour $P$. camemberti, dont l'action lipolytique était également signalée depuis longtemps, une seule lipase à $\mathrm{pH}$ optimal d'action alcalin a été mise en évidence et caractérisée (LAMBERET et LENOIR, 1972, 1976 a).

\section{B. Les lipases alcalines des deux Penicillium}

L'étude de ces enzymes a été réalisée sur des préparations exocellulaires, après précipitation au sulfate d'ammonium pour celle de $P$. roqueforti (EITENMILLER et al., 1970 ; MENASSA et LAMBERET, 1982) et après purification complète par chromatographie d'exclusion et d'échange d'ions pour celle de $P$. camemberti (LAMBERET et LeNOIR, 1976 b). Toutes deux sont plus actives sur la tributyrine que sur les autres triglycérides homogènes et leurs activités relatives sur trioléine sont voisines de $20 \%$ de l'activité sur tributyrine; elles se différencient par leur action sur d'autres substrats tels que la tricapryline et la tricaprine avec des vitesses d'hydrolyse relatives de 91 et $62 \%$ pour la lipase de $P$. roqueforti, de 65 et $27 \%$ pour celle de $P$. camemberti (EITENMiller et al., 1970; Menassa et LAMBeret, 1982 ; LAMBerEt, données non publiées). De même, leur activité relative sur huile de beurre est de $60 \%$ pour la première et $87 \%$ pour la seconde. Enfin, la lipase de $P$. camemberti exerce une action importante sur la triacétine en solution (environ $10 \%$ ) mais, en émulsion, l'hydrolyse de ce substrat est inhibée (LAMBERET et LenOIR, 1976 b).

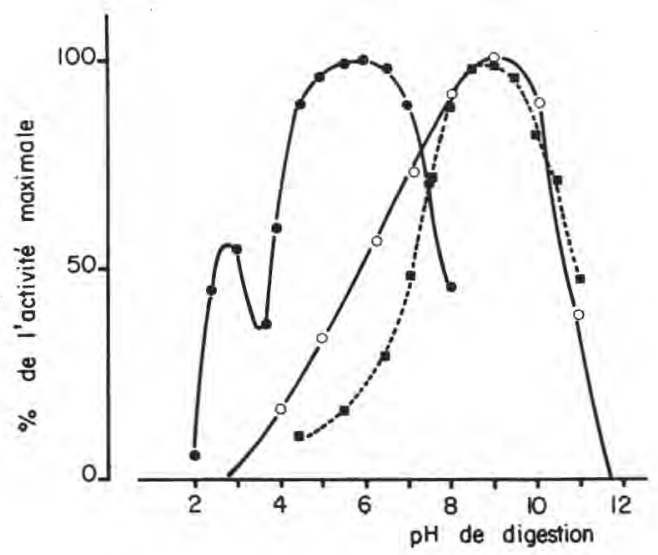

Fig. 6

Influence du pH sur l'activité des lipases de $\mathrm{P}$. roqueforti et de $\mathrm{P}$. camemberti. Activités déterminées à $30^{\circ} \mathrm{C}$ au $\mathrm{pH}$ stat : sur tricaprö̈ne pour la lipase acide de $\mathrm{P}$. roqueforti $\bullet$; sur tributy. rine pour la lipase alcaline de $\mathrm{P}$. roqueforti I et la lipase de P. camemberti 0 .

Influence of $p H$ on the activity of lipases of $\mathrm{P}$. roqueforti and $\mathrm{P}$. camemberti. Activities determined at $30^{\circ} \mathrm{C}$ with the $p H$-stat method. Tricaproin for the acid lipase of $\mathrm{P}$. roqueforti $\bullet$; tributyrin for the alcaline lipase of $\mathrm{P}$. roqueforti and lipase of $\mathrm{P}$. camemberti $\mathrm{O}$. 
Le $\mathrm{pH}$ optimal d'action des deux enzymes se situe vers $9,0-9,5$ à $30{ }^{\circ} \mathrm{C}$ et elles conservent une activité non négligeable jusqu'à $\mathrm{pH} 4,5$. Toutefois, les courbes traduisant l'activité sur tributyrine en fonction du $\mathrm{pH}$ sont sensiblement différentes (fig. 6) ; ainsi, à $\mathrm{pH} 6,5$, la lipase de $P$. roqueforti manifeste $30 \%$ de son activité maximale tandis que celle de $P$. camemberti se situe à plus de $50 \%$ (MENASSA et LAMBERET, 1982). Il a été montré avec $P$. roqueforti que les activités relatives dans les zones de $\mathrm{pH}$ où l'enzyme est peu stable sont modifiées lorsque l'hydrolyse est réalisée à une température inférieure à $30{ }^{\circ} \mathrm{C}$ mais que l'allure générale de la courbe d'activité en fonction du $\mathrm{pH}$ n'en est pas affectée. Ainsi, aux $\mathrm{pH} 4,5$ et 11,0 , les activités mesurées à $20^{\circ} \mathrm{C}$ sont supérieures à celles obtenues à $30^{\circ} \mathrm{C}$. Ce comportement pourrait expliquer, au moins en partie, le $\mathrm{pH}$ optimal de 8,0 à $37^{\circ} \mathrm{C}$, sur émulsion d'huile de beurre, rapporté par EitenMiller et al. (1970).

A pH 9,0, la température optimale d'action est de $35^{\circ} \mathrm{C}$. Lorsque la température augmente de 20 à $30^{\circ} \mathrm{C}$, l'activité se trouve multipliée par un facteur de 1,6 pour la lipase de $P$. roqueforti et de 1,2 seulement pour celle de $P$. camemberti. Les deux lipases présentent aussi des différences quant à l'activation par les cations métalliques. La lipase de $P$. roqueforti est stimulée par la présence d'ions $\mathrm{Mn}^{++}$ou $\mathrm{Mg}++$ (EITENMILler et al., 1970) tandis que ceux-ci sont sans effet sur l'enzyme de $P$. camemberti. Cette dernière est inhibée à $80 \%$ par l'E.D.T.A. ; elle recouvre en grande partie son activité par l'ajout d'ions $\mathrm{Ca}^{++}$, et aussi, mais à un moindre degré, d'ions $\mathrm{Fe}^{++}, \mathrm{Al}^{+++}$ou $\mathrm{Cu}^{++}$. Enfin, certains inhibiteurs spécifiques tels que le pCMB (p-chloromercuribenzoate) ou le DFP inhibent l'enzyme, mais seulement partiellement et pour des concentrations de l'ordre de 0,01M (LAMBERET et LENOIR, 1976 b), ce qui ne permet pas de préciser la nature des groupes fonctionnels impliqués dans la réaction de catalyse.

\section{La lipase acide de $\mathrm{P}$. roqueforti}

LOBYREVA et MARCHENKova (1981) ont séparé trois fractions actives par chromatographie d'échange d'ions à partir d'un filtrat de culture. Par leur $\mathrm{pH}$ optimal d'action en zone acide proche de la neutralité et par leur activité plus grande sur tricaproïne que sur les autres triglycérides, ces fractions sont proches de l'enzyme caractérisée par LAMBeret et Menassa (1983 a).

Dans les cultures de la souche étudiée par ces auteurs, l'enzyme libérée dans le milieu est associée à d'autres protéines avec lesquelles elle semble former un complexe de poids moléculaire supérieur à 500000 . Les essais d'isolement à partir de ce complexe n'ont pas permis de séparer une fraction enzymatique stable. L'activité du complexe sur tributyrine est de $22 \%$ et sur tricapryline de $6 \%$ de celle sur tricaproïne; son activité sur trioléine et sur huile de beurre est plus réduite. Sous cette forme, l'enzyme est stable à $30^{\circ} \mathrm{C}$ entre les $\mathrm{pH}$ de 3,7 à 6,0 et le $\mathrm{pH}$ optimal d'activité se situe, à cette température, à 6,0 mais il est de 6,5 à $20^{\circ} \mathrm{C}$. Après un minimum à $\mathrm{pH} 3,6$, les courbes d'activité en fonction du $\mathrm{pH}$ présentent un maximum secondaire à $\mathrm{pH} 3,0$ de valeur proche de la moitié de celle de l'optimum principal (fig. 6). La stabilité de la préparation en fonction

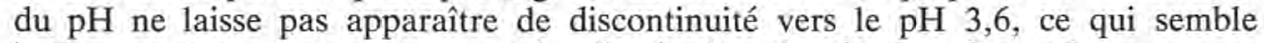
indiquer qu'une seule enzyme est impliquée dans la réaction de catalyse.

A pH 6,5 , la température optimale d'action est de $35-40{ }^{\circ} \mathrm{C}$ et le Q 10 entre 20 et $30^{\circ} \mathrm{C}$ varie de 2,1 à 1,2 dans la zone de $\mathrm{pH}$ allant de 4,0 à 7,0 . En 
présence de calcium à la concentration $0,1 \mathrm{M}$, l'enzyme est partiellement inactivée, avec un effet plus marqué aux $\mathrm{pH}$ alcalins qu'aux $\mathrm{pH}$ acides; la valeur minimale d'inactivation de $8 \%$ est observée à pH 5,0. L'inhibition est faible aux concentrations en calcium inférieures ou égales à $0,01 \mathrm{M}$.

\section{Production de lipases}

Le $\mathrm{pH}$ est un facteur important de production de l'une et l'autre lipases de $P$. roqueforti : à un $\mathrm{pH}$ initial de culture de 4,0 , l'activité mesurée à $\mathrm{pH} 6,0$ est supérieure à celle mesurée à $\mathrm{pH} 7,5$ et le phénomène est inversé avec un $\mathrm{pH}$ initial de 8,0 (NIKI et al., 1966). Ainsi, la tendance de la moisissure à alcaliniser le milieu, au moins pendant la seconde phase de croissance, favorise-t-elle la présence de lipase alcaline dans les cultures âgées. L'aération des cultures par agitation permet une croissance plus précoce et finalement une production de lipase alcaline exocellulaire plus rapide et plus élevée que dans les cultures non agitées (EITENMILlER et al., 1970).

La lipase acide n'est produite en quantité importante sans agitation qu'à basse température, par exemple à $7{ }^{\circ} \mathrm{C}$ pendant 30 jours (IMAMURA et KaTAOKA, 1963 a). En milieu agité, la température de $25^{\circ} \mathrm{C}$ convient pour une production de cette lipase en 3-4 jours, l'activité exocellulaire maximale étant obtenue avant que le $\mathrm{pH}$ ne dépasse les valeurs de 6,0-6,3 (Menassa, 1981).

Comme pour la production de nombreuses enzymes, les sources complexes d'azote sont plus favorables que les formes minérales. Des hydrolysats de caséine, en mélange ou non avec des protéines végétales, ont été notamment utilisés (EitenMiller et al., 1970 ; MenAssa, 1981).

L'addition dans les cultures d'huile de beurre ou d'un ester tensioactif comme le Tween 20 a un effet beaucoup plus complexe. Leur présence est favorable à la production de lipase acide, en particulier elle limite l'effet inhibiteur que peuvent présenter certaines sources de carbone ou certains anions comme les phosphates ou le succinate (Menassa, 1981). La production de cette enzyme est réduite en présence des oligo-éléments de la solution de MEYER et KNIGHT (1958).

L'huile de beurre a une influence défavorable à la production de lipase alcaline en présence de glucose (EITENMILler et al., 1970) tandis qu'elle peut être utilisée de façon avantageuse en absence d'une autre source simple de carbone (Morris et Jezeski, 1953 ; Imamura et KataoKa, 1963 a; Menassa, 1981). La production est également augmentée en présence de phosphates et d'oligoéléments.

Pour $P$. camemberti, la production de lipase en culture non agitée apparaît aussi très sensible aux variations de $\mathrm{pH}$. Aux $\mathrm{pH}$ acides, la quantité de lipase est réduite et essentiellement associée au mycélium. Le $\mathrm{pH} 7,5$ est très favorable malgré une masse mycélienne relativement faible (LAMBERET et LeNOIR, 1972) mais le temps de culture optimal, 12 jours à $20^{\circ} \mathrm{C}$, reste long. La production est plus forte en présence d'une source complexe d'azote qu'avec l'azote minéral ; l'huile de beurre a un effet inhibiteur.

En culture agitée, divers milieux de base et sources nutritives organiques ont été systématiquement expérimentées (AL-HIR et al., $1980 \mathrm{a}$ et b). La production de lipase est plus stimulée par l'huile de maïs que par d'autres matières grasses et elle peut être précoce, avec un maximum après 3 jours d'incubation. Un hydro- 
lysat de graine de soja (soytone) est une meilleure source d'azote que la caséine ou ses hydrolysats (AL-HIR et al., 1980 a et b). Parmi les sucres, le glucose et le saccharose apparaissent les plus favorables (AL-HrR et CHANDAN, 1981). Des conditions de production en fermenteur industriel ont également été décrites (BELloc et al., 1975).

\section{E. Lipolyse dans les pâtes fromagères}

Dans les fromages affinés par les Penicillium, même dans les fromages de lait cru, l'activité lipasique se manifeste surtout au voisinage du mycélium, les enzymes diffusant très peu au sein de la pâte. Ainsi les acides gras libres sont localisés principalement dans la partie centrale des bleus (GodinHo et Fox, 1981 b) et sous la croûte dans le cas du camembert (KuzDZaL-Savoie, 1968).

Dans les bleus, les activités lipasiques ont pu être déterminées sur le mycélium colonisant les cavités du fromage et les quantités respectives des lipases acide et alcaline produites ont été estimées (LAMBERET et MENASSA, 1983 b) ; des variations importantes dans les niveaux d'activité ont été mises en évidence entre les échantillons, montrant l'influence du choix des souches, de l'âge du fromage ou du $\mathrm{pH}$ de la pâte. Pour le camembert traditionnel, l'activité lipasique du Penicillium est maximale vers le $16^{\mathrm{e}}$ jour et, dans un fromage affiné, l'activité du mycélium mesurée sur tributyrine au $\mathrm{pH}$ du fromage $(6,8$ à 7,2$)$ peut représenter de 1,2 à 4,45 UL ( $\mu$ éq. acide libérés par minute) par gramme de croûte (LAMBERET et LOPEZ, 1972).

Les deux types de fromage sont caractérisés par des taux d'acides gras libres particulièrement élevés qui sont, pour plus de $95 \%$, d'origine lipolytique. Dans les roqueforts, le degré de lipolyse est de 7 à $12 \%$ (e.g. ANDERson et DAY, 1965) ; dans les bleus fabriqués avec du lait de vache et de provenances diverses, les valeurs sont généralement supérieures à $10 \%$ et elles atteignent parfois 18 à $25 \%$ (e.g. Anderson et DAy, 1965 ; Jensen, 1974 a). Dans les camemberts normands, les degrés de lipolyse sont très variables et se situent entre 6 et $10 \%$ (KuzDzal et Kuzdzal-Savole, 1966), mais des taux plus faibles de 3 à $5 \%$ ont également été rapportés (VANBElle et al., 1978).

Le profil des acides gras libres qui devrait traduire les spécificités de substrat des lipases impliquées est assez voisin de celui de la matière grasse initiale (fig. 7). Quelques différences peuvent cependant être relevées pour certains acides, en particulier dans le cas du camembert où la proportion d'acide oléique est plus grande parmi les acides gras libres que dans les triglycérides. Ceci pourrait être dû à la présence en surface de ce fromage de Geotrichum candidum, produisant une lipase à forte spécificité pour cet acide (KuzDZal et KuzDzal-Savoie, 1966 ; JENSEN, 1974 b) où à la seule spécificité de la lipase du Penicillium pour les acides insaturés (Al-Hir et Chandan, 1982). Dans les bleus, l'emploi de souches différentes de $P$. roqueforti conduit à des niveaux variables de lipolyse mais aussi à des profils d'acides gras volatils différents (STEPANIAK et al., 1974), probablement du fait des quantités respectives des deux lipases. Ce fait n'est pas sans incidence pratique sur le plan de la flaveur car ce sont les acides gras à chaîne courte ou moyenne, de 4 à 12 atomes de carbone, qui présentent le plus d'intérêt, directement ou comme précurseurs d'arôme, bien que le niveau global de lipolyse, entre autres paramètres, doive aussi être pris en compte. 
Les glycérides partiels, autres produits de la lipolyse, ont été peu étudiés ; si l'on se réfère aux travaux de VuJICIC et DE MAN (1967), les proportions d'acides gras courts, en particulier d'acide butyrique, dans ces glycérides semblent être beaucoup plus faibles dans le cas du camembert que dans les bleus et que dans la plupart des autres fromages analysés par ces auteurs.

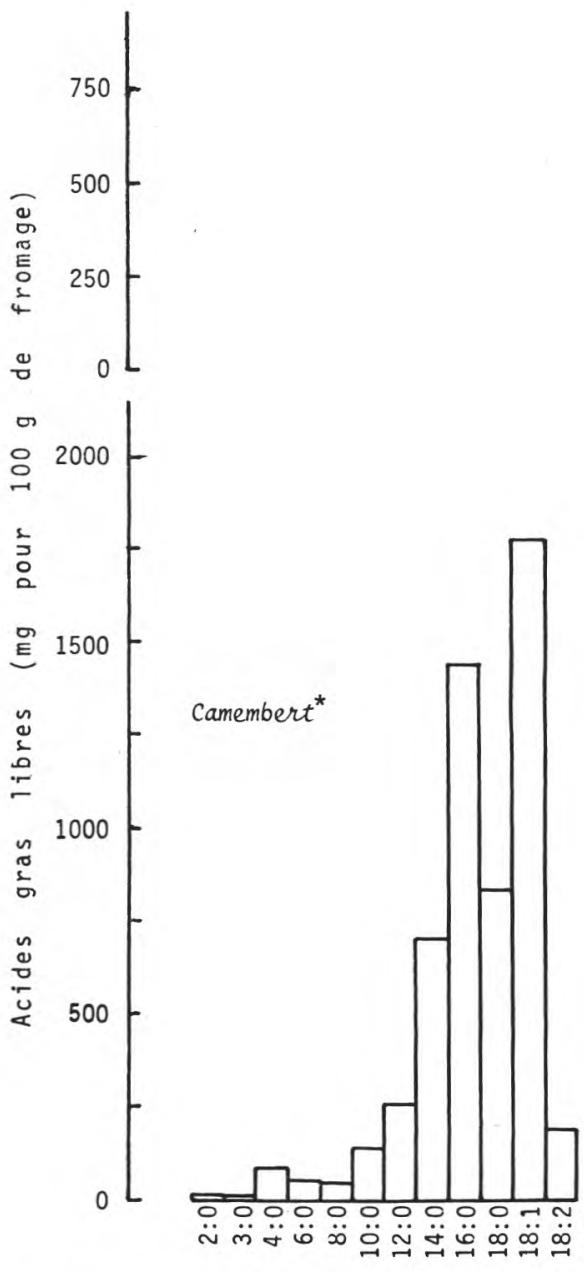

*d'après KUZDZAL-SAVOIE et KUZDZAL (1966)
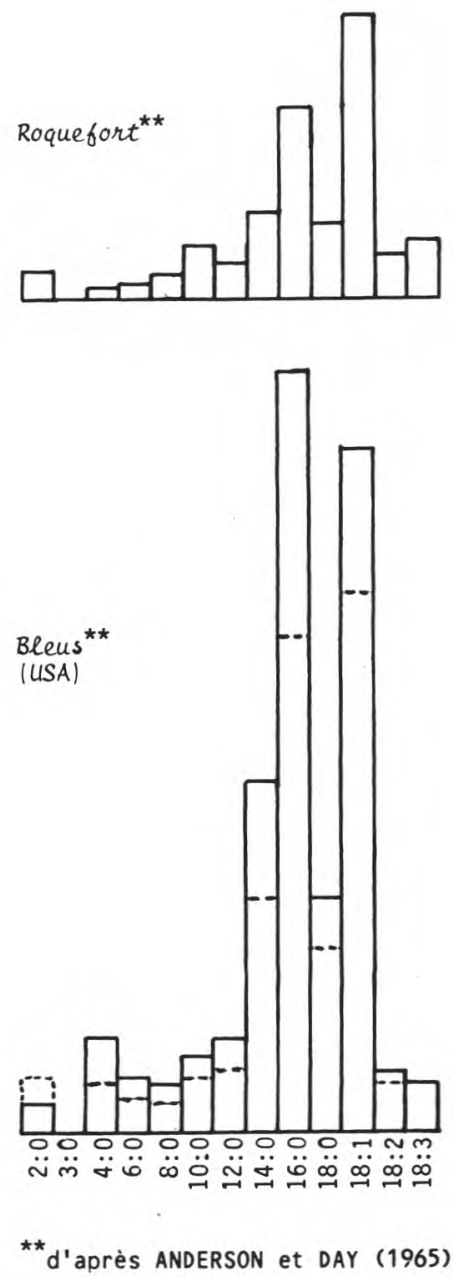

Fig. 7

Comparaison des profils des principaux acides gras libres des camemberts et des bleus.

Comparison of the main free fatty acids in camemberts and blue veined cheese. 


\section{Autres activités biochimiques}

\section{A. La dégradation des acides aminés}

La dégradation d'une partie des acides aminés libérés par la protéolyse représente un phénomène biochimique important dans l'affinage des fromages, notamment dans la formation de la saveur et de l'arôme (CHOISY et al., 1984; ADDA, 1984). Dans le schéma général du catabolisme microbien des acides aminés, Hemme et al. (1982) distinguent trois niveaux de réaction (fig. 8). Le premier concerne l'action des décarboxylases, des transaminases, des désaminases et des enzymes dégradant les chaînes latérales ; il est notamment à l'origine de la formation d'amines et d'acides $\alpha$-cétoniques. Ceux-ci peuvent à leur tour, dans le deuxième niveau de réaction, être transformés en aldéhydes essentiellement sous l'action de désaminases ou de décarboxylases. Dans le troisième niveau, les aldéhydes peuvent être eux-mêmes réduits en alcools par les réductases ou transformés en acides par les oxydases.

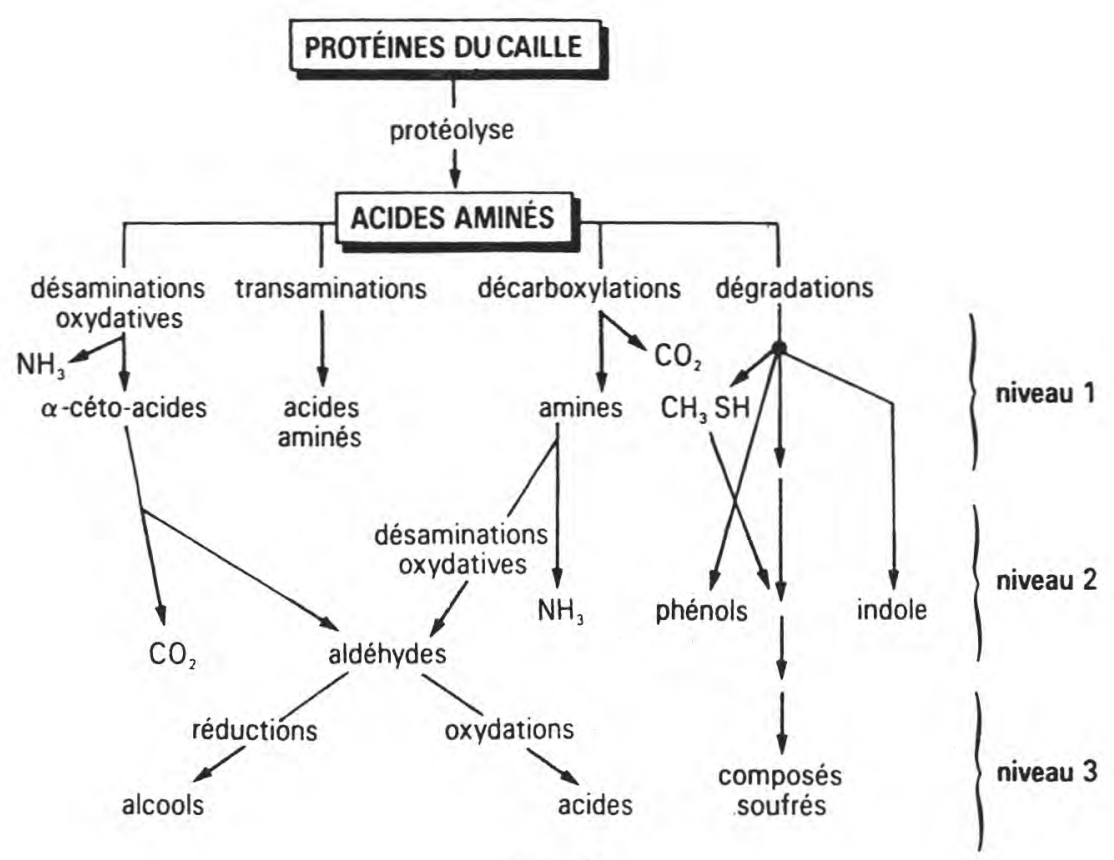

Fig. 8

Schéma général du catabolisme microbien des acides aminés au cours de l'affinage des fromages (d'après HEMME et al., 1982).

Schematic presentation of the microbial catabolisme of amino acids during ripening of cheese. (Hemme et al., 1982). 
La composition en acides aminés libres des fromages est donc la traduction d'un ensemble complexe de réactions. Ils ont pour principale origine l'hydrolyse des protéines du fromage mais leurs proportions relatives peuvent être notablement modifiées du fait des remaniements ou des dégradations enzymatiques, des excrétions ou des lyses microbiennes. Il s'ensuit que chaque type de fromage est caractérisé par un profil d'acides aminés qui lui est propre (Do NGOc et al., 1971). Certains acides aminés sont présents dans les fromages et non dans les caséines, tel est le cas de l'acide $\gamma$-aminobutyrique ou de l'ornithine. D'autres sont présents à des taux plus faibles ou, au contraire, plus élevés que dans la caséine. Ainsi les fromages de camembert affinés sont caractérisés par la présence d'une proportion relativement élevée d'acide $\gamma$-aminobutyrique et de faibles quantités de sérine, de lysine et d'arginine. Par ailleurs, ces fromages contiennent de très fortes teneurs en azote ammoniacal (LENOIR, 1962).

La part des Penicillium dans la dégradation des acides aminés est difficile à préciser car les études sur le sujet sont peu nombreuses. CECCHI et Resmini (1972, 1973 ) et CECCHI et al. (1973) ont montré que les moisissures sont les principaux agents responsables de la décarboxylation et de la dégradation de l'arginine. Selon ces auteurs, l'arginine est dégradée en urée et en ornithine avec, comme produit intermédiaire possible, la citrulline. Les acides $\gamma$-aminobutyrique et $\alpha$-guanidobutyrique sont également reconnus comme des produits de dégradation de l'arginine.

La dégradation de la méthionine présente un intérêt particulier en raison de l'importance des composés soufrés volatils dans le développement de l'arôme des fromages de type camembert (ADDA, 1984). P. camemberti pourrait être responsable de cette dégradation ; il possède, en effet, des enzymes qui sont capables d'assurer la libération du méthanethiol par coupure de la liaison carbonesoufre (Tsugo et Matsuoka, 1962) et ce composé est le précurseur de nombreux autres produits soufrés porteurs d'arôme (ADDA et al., 1982).

\section{B. La formation de méthylcétones à partir des acides gras}

Comme un certain nombre de moisissures appartenant à diverses espèces, $P$. roqueforti et $P$. camemberti possèdent une voie métabolique originale conduisant, à partir des acides gras saturés à chaîne courte et moyenne, à des cétones (e.g. Frank et Heinen, 1958). Cette voie se greffe sur la voie normale de la $\beta$-oxydation des acides gras et les cétones résultantes possèdent un atome de carbone de moins que l'acide originel par perte du carbone du groupe carboxylique (Lawrence, 1966). Kinsella et Hwang (1976 a et b) ont présenté une synthèse des travaux relatifs à la formation des méthylcétones par $P$. roqueforti dans deux revues bibliographiques d'où est tiré le schéma de la figure 9 . La présence d'une activité thiohydrolase dont le substrat préférentiel est le $\beta$-céto octanoyl-CoA a été démontrée et le système responsable de l'activité $\beta$-cétoacyl décarboxylase a été partiellement purifié. Deux formes, l'une thermolabile et l'autre thermostable, sont présentes dans les préparations brutes exocellulaires (Hwang et al., 1976); son substrat préférentiel est l'acide $\beta$-cétolaurique. La réaction de production des méthylcétones est maximale dans l'intervalle de $\mathrm{pH} 5,0-7,0$ et la présence d'un faible taux de $\mathrm{CO}_{2}$ endogène favorise cette voie de dégradation au détriment de la voie normale. Le mycélium semble la forme cellulaire la plus active pour cette transformation mais elle se produit également 
avec les spores en germination ou les spores au repos, et, dans ce cas, elle est augmentée par apport d'énergie sous forme de glucose.

Les méthylcétones ainsi formées ne s'accumulent pas, elles sont ensuite métabolisées par la moisissure. Dans les fromages, elles sont en partie réduites par

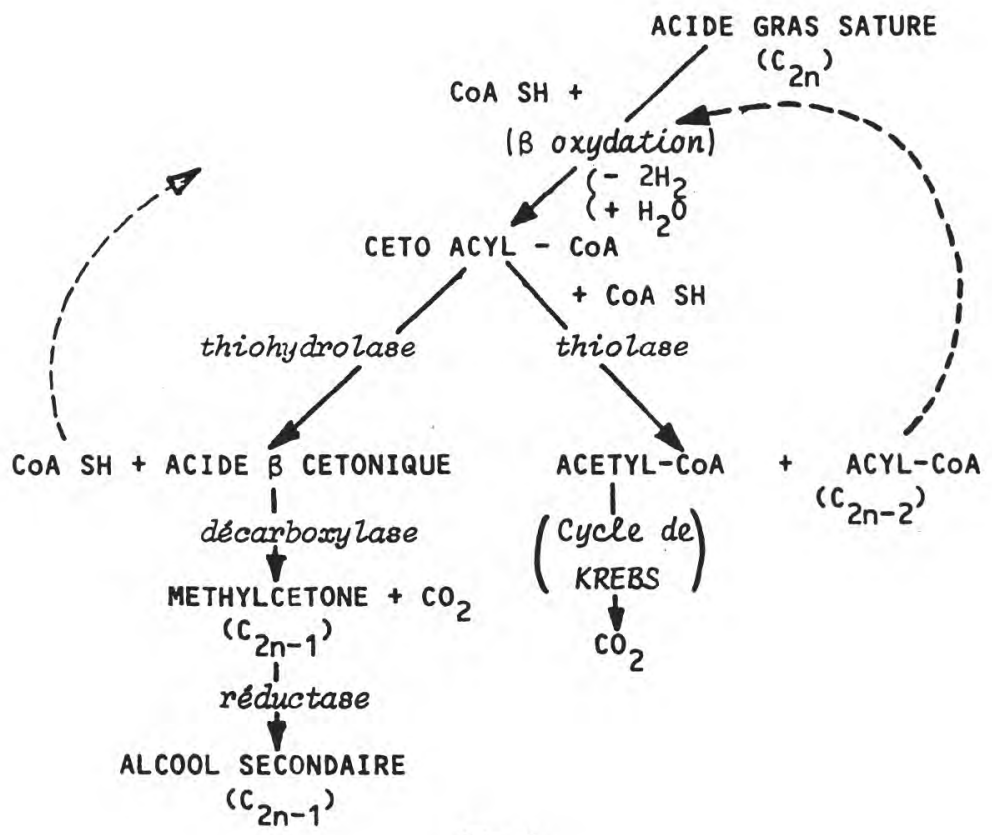

Fig. 9

Transformation des acides gras par oxydation (d'après KINSELla et HWANG, 1976 b).

Fatty acid transformation by oxidation.

TABlEAU IV

Méthylcétones dans la matière grasse de fromage bleu (résultats exprimés en $\mu \mathrm{g}$ pour $10 \mathrm{~g}$ de matière grasse) (d'après ScHWARTZ et PARKS, $1963 \mathrm{a}$ )

Methylketones in the fat of blue veined cheese (results expressed as $\mu \mathrm{g} 10 \mathrm{~g}$ fas) (ScHWARTZ and PARKS, 1963 a)

\begin{tabular}{|c|c|c|c|c|c|c|c|}
\hline Echantilion & $\begin{array}{c}\text { Age de } \\
\text { I'échantilion }\end{array}$ & $\left(c_{15}+c_{13}\right)$ & $c_{11}$ & $C_{9}$ & $c_{7}$ & $c_{5}$ & $c_{3}$ \\
\hline A & 2 mois minimum & 1,1 & 1,7 & 7,6 & 30,2 & 20,0 & 5,1 \\
B & 3 mois minimum & 0,8 & 0,7 & 2,5 & 3,4 & 0,9 & trace \\
C & 4 mois minimum & 1,3 & 1,7 & 8,5 & 12,4 & 7,2 & trace \\
\hline
\end{tabular}


Concentration en méthylcétones du Roquefort

( $m g$ pour $10 \mathrm{~g}$ de matière grasse)

(d'après ScHWARTZ et al., 1963)

Concentration of methylketones of Roquefort cheese ( $m g / 10 \mathrm{~g}$ fat)

(SchWARTZ et al., 1963)

\begin{tabular}{|c|c|c|c|c|c|c|}
\hline Echanti1lon & $\left(c_{15}+c_{13}\right)$ & $c_{11}$ & $c_{9}$ & $c_{7}$ & $c_{5}$ & $c_{3}$ \\
\hline 1 & 0,5 & 0,7 & 7,4 & 15,6 & 11,0 & 2,4 \\
2 & 0,4 & 1,6 & 12,4 & 9,2 & 1,2 & 0 \\
3 & 0,3 & 0,3 & 2,6 & 4,2 & 0 & 0 \\
\hline
\end{tabular}

TABLEAU $\mathrm{V}$

Production de méthylcétones à partir des acides caprylique et laurique par le mycélium de Penicillium camemberti (résultats exprimés en micromoles par gramme) (LAMBERET et al., 1980)

Production of methylketones from caprylic and lauric acid by the mycelium of Penicillium camemberti (results expressed in micromol/g)

(LAMBERET et al., 1980)

\begin{tabular}{|c|c|c|c|c|}
\hline \multirow[b]{2}{*}{ Souches } & \multicolumn{4}{|c|}{ Production de } \\
\hline & \multicolumn{2}{|c|}{ heptanone } & \multicolumn{2}{|c|}{ undecanone } \\
\hline & $2 \mathrm{~h}$ & $4 \mathrm{~h}$ & $2 \mathrm{~h}$ & $4 \mathrm{~h}$ \\
\hline P1 & 1.1 & 3.75 & 08 & \\
\hline P12 & 4.1 & 13,5 & 0,8 & $0, y$ \\
\hline P16 & 3,2 & 7,9 & 0,45 & 2,1 \\
\hline PA15 & 3,0 & 11,2 & 0,55 & 1,2 \\
\hline PB1 & 3,9 & 8,2 & 0,7 & 1,8 \\
\hline PC2 & 6,7 & 18,0 & 0,85 & 2,1 \\
\hline PC8 & 6,3 & 22,1 & 0,85 & 1,95 \\
\hline $\mathrm{PC} 12$ & 7,9 & 32,2 & 1,3 & 1,95 \\
\hline PEI & 6,2 & 23,2 & 1,5 & 2,4 \\
\hline PL2 & 3,2 & 1,1 & 0,7 & 0,3 \\
\hline PL3 & 4,9 & 13,9 & 0,7 & 1,3 \\
\hline PL4 & 6,4 & 18,4 & 0,85 & 1,8 \\
\hline PL11 & 6,2 & 25,1 & 1,0 & 2,7 \\
\hline PL21 & 7,2 & 30,0 & 1,1 & 3,1 \\
\hline PN1 & 8,7 & 33,4 & 1,2 & 2,8 \\
\hline PN14 & 8,4 & 27,7 & 1,2 & 2,6 \\
\hline PN19 & 8,7 & 35,6 & 1,25 & 2,5 \\
\hline PN28 & 12,2 & 44,4 & 1,65 & 2,3 \\
\hline
\end{tabular}

voie enzymatique, sous l'action du mycélium de $P$. roqueforti, en alcools secondaires, produits qui peuvent eux-mêmes participer à l'arôme. Il semble d'ailleurs exister un équilibre entre ces deux types de composés, la moisissure pouvant aussi former les cétones à partir des alcools secondaires (JACKsON et Husson, 
1958). Ainsi, King et ClegG (1979) ont observé principalement la formation de méthylcétones et non d'alcools secondaires après ajout des précurseurs potentiels dans un milieu modèle à base de caillé homogénéisé.

Dans les fromages de types bleu, de vache ou de brebis, les taux de méthylcétones apparaissent très variables, de 80 à $650 \mu \mathrm{M}$ pour $100 \mathrm{~g}$ de matière grasse ; la 2-heptanone est dominante puis la 2-nonanone et parfois la 2-pentanone (tabl. IV) (SCHWARTZ et PARKS, 1963 a ; SCHWARTz et al., 1963).

L'activité oxydative du mycélium de $P$. camemberti se manifeste notamment sur l'acide caprylique et à un moindre degré sur l'acide laurique. Sur une collection de 18 souches des différences d'amplitude d'activité proche de 1 à 10 ont été observées (tabl. V). Les souches les plus actives se révèlent être souvent aussi celles qui produisent le plus de lipase exocellulaire (LAMBERET et al., 1982). Dans les fromages de type camembert, les quantités de méthylcétones sont plus faibles que dans les bleus (de 25 à $60 \mu \mathrm{M} / 100 \mathrm{~g}$ ) (SCHWARTz et Parks, $1963 \mathrm{~b}$ ) mais leur rôle dans le développement de la saveur et de l'arôme du fromage n'en est sans doute pas moins important (ADDA, 1984).

La production de méthylcétones à partir de matières grasses pour l'obtention de flaveurs rappelant celles des fromages de type bleu a fait l'objet de divers brevets. Les systèmes préconisés, essentiellement à partir de l'espèce $P$. roqueforti, font intervenir, soit le mycélium seul, soit les spores en germination, avec ou sans mycélium. Avec le premier matériel, une production continue sur 2 semaines peut être obtenue avec un temps moyen de contact de 24 heures entre le mycélium et la crème diluée préalablement hydrolysée (DWIVEDI et KinSELla, 1974 a et b). Les méthylcétones correspondent à $90 \%$ des composés carbonylés produits. La forme du substrat (lait entier, crème, huile de beurre ou acides gras libres) ìnflue sur les profils de méthylcétones obtenus (KANissaWA et ITOH, 1984 a et b). De même, la nature des lipases utilisées pourrait intervenir.

L'aptitude des spores en germination à la production de méthylcétones a été exploitée dans un système en continu avec l'hydrolyse simultanée de l'émulsion de matière grasse laitière ou d'huile de coco par une lipase exogène (JollY' et KosikowsKi, 1975 a et b). Des supports d'arôme contenant des quantités de cétones beaucoup plus importantes que les fromages ont été ainsi obtenus.

Par un processus analogue mais discontinu et sans lipase exogène, il est possible d'obtenir, dans des « caillés fluides» homogénéisés, une aromatisation maximale après 5 jours à $20^{\circ} \mathrm{C}$ (KING et CLEGG, 1979). Malgré le rôle favorable que pourrait jouer la caséine en freinant le catabolisme des méthylcétones (KING et CLEGG, 1980) et en réduisant la concentration apparente des acides gras, les quantités de cétones produites apparaissent cependant bien moindres que dans le modèle précédent.

Les travaux réalisés sur $P$. camemberti sont beaucoup moins nombreux. Récemment avec le mycélium de cette moisissure OKUMURA et Kinsella (1985) ont produit sur un milieu à base de lait avec ajout de matière grasse laitière lipolysée des arômes où les méthylcétones représentent $60 \%$ des carbonylés totaux.

\section{Activités phosphohydrolasiques}

Diverses activités phosphohydrolases liées au mycélium ont été mises en évidence dans le cas de P. camemberti (FANNI, 1983). Ainsi ont été reconnues les 
présences d'une phosphatase acide, de $\mathrm{pH}$ optimal 4,0, d'une phosphatase acaline, d'une pyrophosphatase, d'une polyphosphatase, de $\mathrm{pH}$ optimal d'environ 8,0, et d'une phospholipase $\mathrm{C}$, de $\mathrm{pH}$ optimal 7,4. Les températures optimales d'action de ces enzymes se situent entre 40 et $50^{\circ} \mathrm{C}$.

Une étude conduite sur 16 souches déjà connues pour leurs activités protéolytiques et lipolytiques a par ailleurs montré des différences importantes entre les souches dans les niveaux de production des phosphatases, acide et alcaline, mesurés sur p-nitrophényl phosphate (AuBERGer et al., données non publiées). D'une façon générale, il apparaît que l'activité phosphatase acide du mycélium obtenu par culture à $\mathrm{pH} 4,0$ ou $\mathrm{pH} 6,5$ est plus élevée que l'activité phosphatase alcaline. Dans le milieu de culture, ces activités se situent à des niveaux plus faibles que sur le mycélium.

Bien que les deux activités phosphatasiques de la moisissure se situent à des niveaux relativement élevés, aucune action de déphosphorylation n'a pu être mise en évidence in vitro sur caséine isoélectrique ou sur caséine $\alpha_{81}$, ni sur phosphosérine ou phosphothréonine, aux valeurs de $\mathrm{pH}$ de 4,5 et 8,0 .

\section{Conclusion}

Les deux Penicillium possèdent ainsi des caractères communs et des caractères distinctifs. Outre leur parenté taxonomique, liée à des caractères physiologiques et morphologiques, figurent parmi les premiers les potentialités enzymatiques particulièrement intéressantes en fromagerie, principalement la protéolyse et la transformation des acides aminés, la lipolyse et la dégradation oxydative des acides gras. Certaines de ces activités présentent d'ailleurs de grandes analogies. Ainsi, un apparentement très marqué dans la nature des systèmes protéolytiques a été mis en évidence, de même certaines similitudes ont été observées dans les caractéristiques d'action des lipases alcalines et dans les voies de dégradation des acides gras.

Il y a toutefois des différences importantes dans le comportement physiologique ou dans certaines activités biochimiques des deux espèces. $P$. roqueforti se développe beaucoup plus rapidement que $P$. camemberti, aussi bien sur milieu gélosé qu'en milieu liquide; alors que la croissance maximale de la première est atteinte en 3-4 jours, celle de la seconde en exige 12 à 15 . Le comportement aérobie est aussi très différent, $P$. roqueforti étant caractérisé par son aptitude à se développer en présence de faibles taux d'oxygène. Les variations dans le $\mathrm{pH}$ des cultures sur milieu de Czapek constituent un autre exemple de distinction, $P$. roqueforti acidifie d'abord le milieu puis l'alcalinise alors que $P$. camemberti tend plutôt à l'amener au voisinage de la neutralité, et cette différence est l'indice de voies métaboliques propres à chacune des espèces. La marque de comportements physiologiques différents est également apportée par la plus ou moins grande aptitude à la culture et à la production d'enzymes en fermenteur. La production d'enzymes protéolytiques par $P$. roqueforti est, dans ces conditions, optimale et rapide ; elle n'a pas encore, à ce jour, été réalisée avec $P$. camemberti. 
Parmi les activités biochimiques, certaines n'appartiennent qu'à l'une des moisissures. Il en est ainsi en particulier de la lipase acide, une enzyme de spécificité marquée pour la tricaproïne, que seule $P$. roqueforti possède.

A ces caractères distinctifs, dont la liste n'est pas limitative, s'ajoute une autre différence importante probablement liée à l'écologie de chacune des espèces - l'habitat unique de $P$. camemberti, les fromages et les caves d'affinage, face à l'ubiquité de $P$. roqueforti - la très grande variabilité de caractères de $P$. roqueforti alors que $P$. camemberti se singularise par une relative homogénéité.

Reçu le 9 mai 1986

Accepté pour publication le 14 juillet 1986

\section{Références bibliographiques}

ADDA P., 1984. Les propriétés organoleptiques des fromages : formation de la flaveur. In : Le Fromage, éd. A. Eck, Lavoisier Paris, 330-340.

ADDA J., GRIPON J.C., VASSAL L., 1982. The chemistry of flavour and texture generation in cheese. Food Chem., 9, 115-129.

Aнiкo K., Iwasawa S., Ulda M., Mryata N., 1981 a. Studies on acid carboxypeptidase from Penicillium caseicolum. I. Purification and properties of acid carboxypeptidase. Rep. Res. Lab. Snow Brand Milk Prod. Co., $\mathrm{n}^{\circ}$ 77, 127-134.

Ahiko K., Iwasawa S., Ulda M., Mixata N., 1981 b. Studies on acid carboxypeptidase from Penicillium caseicolum. II. Hydrolysis of bitter peptides by acid carboxypeptidase and large scale preparation of the enzyme. Rep. Res. Lab. Snow Brand Milk Prod. Co., $\mathrm{n}^{\circ} 77,135-140$.

AL-Hir S., Chandan R.C., Stevenson K.E., 1980 a. Effect of oil addition on lipase production by Penicillium caseicolum. J. Dairy Sci., 63, suppl. 1, 45.

AL-Hir S., Chandan R.C., Stevenson K.E., 1980 b. Effect of different nitrogen sources on growth and lipase production by Penicillium caseicolum. J. Dairy Sci., 63, suppl. 1, 45.

Al-Hir S., Chandan R.C., 1982. Lipase activity of Penicillium caseicolum. J. Dairy Sci., 65, suppl. 1, 63.

ANDERSON D.F., DAY E.A., 1965. Quantitative analysis of the major free fatty acids in blue cheese. J. Dairy Sci., 48, 248-249.

Auberger B., Montals M., Lenorr J., 1982. Etudes du système aminopeptidasique de Penicillium caseicolum. XXI Int. Dairy Cong., Vol. 1, Book 2, 276.

Auberger B., LAMBeret G., Lenoir J., 1985. Les activités enzymatiques de Penicillium camemberti. Sci. Aliments, 5, $\mathrm{n}^{\circ}$ hors série, V, 239-243.

BAKALOR S., 1962 a. Research related to the manufacture of blue veined cheese. Part I. Dairy Sci. Abstr., 24, 529-535.

BAKaLOR S., 1962 b. Research related to the manufacture of blue veined cheese. Part II. Dairy Sci., Abstr., 25, 583-593.

Belloc A., Florent J., Palla J.C., Verrier J., 1975. New lipase and its preparation. Brit. Pat., 1, 403, 847.

Cecchi L., RESMINI P., 1972. Studi sulla degradazione degli aminoacidi liberi nel corso delle maturazione dei frommagi mediante l'uso di traccianti radiotivi. Nota I. L'arginina nella maturazione del fromaggio Gorgonzola. Sci. Tec. Latt. Casearia, 23, 389-409.

Cecchi L., Resmini P., 1973. La degradazione dell'argina nel fromaggio Gorgonzola. Nota III. Influenza della diversa microflora presente. Latte, 47, 3-4. 
Cecchi L., SARacchi S., Resmini P., 1973. Alcuni aspetti della degradazione dell'arginina nel fromaggio Gorgonzola. Nota II. Latte, 47, 3-10.

Chorsy C., Gueguen M., Lenoir J., Schmidt J.L., Tourneur C., 1984. L'affinage du fromage. 1. Les phénomènes microbiens. In : Le Fromage, éd. A. Eck, Lavoisier Paris, 259-290.

Cogmill D., 1979. The ripening of blue veined cheese ; a review. Aust. J. Dairy Sci. Technol., $34,72-75$.

Cunningham A., Wang H.M. Jones S.R., KuRosky A., Rao L., HarRis C.I., RHeE S.H., HofmanN T., 1976. Amino acid sequence of penicillopepsin. IV. Myxobacter AL-1 protease II and Staphylococcus aureus fragments and homology with pig pepsin and chymosin. Can. J. Biochem., 54, 902-914.

Desmazeaud M.J., Gripon J.C., Le Bars D., Bergere J.L., 1976. Etude du rôle des microorganismes et des enzymes au cours de la maturation des fromages. III. Influence des micro-organismes. Lait, 56, 379-396.

Devoyod J.J., BRET G., AuclatR J.E., 1968. La flore microbienne du Roquefort. I. Son évolution au cours de la fabrication et de l'affinage. Lait, 48, 613-629.

Do NGoc M., Lenoir J., Choisy C., 1971. Les acides aminés libres des fromages affinés de Camembert, Saint-Paulin et Gruyère de Comté. Rev. Lait. fr., (288), 447-462.

DwIVEDI B.K., Kinsella J.E., 1974 a. Carbonyl production form lipolyzed milk fat by the continuous mycelial culture of Penicillium roqueforti. J. Food Sci., 39, 83-87.

DWIVEDI B.K., KINSELLA J.E., 1974 b. Continuous production of blue-type flavor by submerged fermentation of Penicillium roqueforti. J. Food Sci., 39, 620-622.

Eitenmiller R.R., 1968. Production and properties of a Penicillium roqueforti lipase. Thèse de « Master of Science », Lincoln, Nebraska (U.S.A.).

EITENMILler R.R., VAKIL J.R., Shahani K.M., 1970. Production and properties of Penicillium roqueforti lipase. J. Food Sci., 35, 130-133.

ENGEL G., TeUBER M., 1978. Simple aid for the identification of Penicillium roqueforti Thom. Growth in acetic acid. Eur. J. Appl. Microbiol. Biotechnol., 6, 107-111.

FANNI J.A., 1983. Phosphohydrolase activities of Penicillium caseicolum. Milchwissenschaft, $38,523-526$.

FODOR P.J., CHARI A., 1979. The ester-hydrolysing enzyme systems of Aspergillus niger or and of Penicillium roqueforti. Enzymol., 13, 258.

Forge M., Guiraud J.P., Galzy P., 1977. Etude d'un accident de fabrication du fromage de Roquefort. Lait, 57, 24-36.

Fournet G.P., 1971. Etude de 1'hétérogénéité des Penicillia roqueforti et de son influence sur l'affinage des fromages de Roquefort. Thèse. Université des Sciences et Techniques du Languedoc, Montpellier.

Franke W., Heinen W., 1958. Uber die Methyl Ketone Bildung durch Schimmelpilze. Arch. Mikrobiol., 31, 50.

GopinHo M., Fox P.F., 1981 a. Effect of $\mathrm{NaCl}$ on the germination and growth of Penicillium roqueforti. Milchwissenschaft, 36, 205-208.

GodinHo M., Fox P.F., 1981 b. Ripening of blue cheese. Influence of salting rate on lipolysis and carbonyl formation. Milchwissenschaft, 36, 476-478.

GoTTLIEB D., 1946. Utilization of amino acids as a source of carbon by fungi. Arch. Biochem., 9, 341-351.

GRIPON J.C., BERGERE J.L., 1972. Le système protéolytique de Penicillium roqueforti. I. Conditions de production et nature du système protéolytique. Lait, 52, 497-513.

GrIPON J.C., Hermier J., 1974. Le système protéolytique de penicillium roqueforti. III. Purification, propriétés et spécifité d'une protéase inhibée par 1'EDTA. Biochimie, $56,1323-1332$.

GRIPON J.C., DEBEST B., 1976. Etude électrophorétique du système protéolytique exocellulaire de Penicillium roqueforti. Lait, 56, 423-438.

GRIPON J.C., 1977 a. Le système protéolytique de Penicillium roqueforti. IV. Propriétés d'une carboxypeptidase acide. Ann. Biol. Anim. Biochim. Biophys., 17, 283-298.

GRIPON J.C., 1977 b. Proteolytic system of Penicillium roqueforti. V. Purification and properties of an alkaline aminopeptidase. Biochimie, 59, 679-686. 
Gripon J.C., Desmazeaud M.J., Le Bars D., Bergere J.L., 1977 a. Role of proteolytic enzymes of Streptococcus lactis, Penicillium roqueforti and Penicillium caseicolum during cheese ripening. J. Dairy Sci., 60, 1532-1538.

GRIPON J.C., RHEE S.H., HofmAnN T., 1977 b. N-terminal amino acid sequence of acid proteases from Penicillium roqueforti and Rhizopus chinensis, alignement with penicillopepsine and mammalian proteases. Can. J. Biochem., 55, 504-506.

GRIPON J.C., 1978. Le système protéolytique exocellulaire de Penicillium roqueforti. Thèse d'Etat, Université de Caen (France).

GRIPON J.C., AUBERGer B., L.eNOIR J., 1980. Metalloproteases from Penicillium caseicolum and Penicillium roqueforti. Comparison of specificity and chemical characterization. Int. J. Biochem., 12, 451-455.

GRIPON J.C., HOFMANN T., 1982. Inactivation of aspartyl proteinases by butane-2,3-dione. Modification of tryptophan and tyrosine residues and evidence againts reaction of arginines residues. Biochem .J., 193, 55-65.

Hayashr R., Moore S., Stein W.H., 1973. Carboxypeptidase from yeast. Large scale preparation and application to $\mathrm{COOH}$-terminal analysis of peptides and proteins. $J$. Biot. Chem., 248, 2296-2302.

Hemme D., Boulllanne C., Metro F., Desmazeaud M.J., 1982. Microbial catabolism of amino acids during cheese ripening. Sci. Aliments, 2, 113-123.

HoumaRD J., RAYMond M.N., 1979. Further characterization of Penicillium roqueforti acid protease. Biochmie, 61, 979-982.

Hwang D.H., Lee Y.L., Krnsella J.E., 1976. $\beta$-ketoacyl decarboxylase activity in spores and mycelium of Penicillium roqueforti. Int. I. Biochem., 7, 165-171.

IChishima E., TAKeuchi M., YaMamota K., SANo Y., KikuchI T., 1978. Intracellular acid carboxypeptidase of Penicillium roqueforti isolated from blue cheese. Curr. Microbiol., 1, 95-98.

IMAMURA T., KATAOKA K., 1963 a. Biochemical studies on the manufacturing of Roquefort type cheese. I. Lipase-producing ability of Penicillium roqueforti. Jpn. J. Zootech. Sci., 34, 344-348.

ImamuRa T., KATAOKa K., $1963 \mathrm{~b}$. Biochemical studies on the manufacturing of Roquefort type cheese. II. Characteristics of lipases produced by Penicillium roqueforti. Jpn. J. Zootech. Sci., 34, 138-142.

IMAMURA T., KATAOKA K., 1966. Biochemical studies on the manufacturing of Roquefort type cheese. III. Isolation of lipases of mould culture. Jpn. J. Dairy Sci., 15, 138-142.

JACKSON H.W., Hussong R.V., 1958. Secondary alcohols in blue cheese and their relation to methylketones. J. Dairy Sci., 41, 920-924.

Jacquet J., Villette O., Delacroix J., Gandouin H., Desfleurs M., 1955. Considérations sur l'action du $\mathrm{pH}$ dans la croissance des moisissures pour la fabrication du Camembert. Rôle du sel. Bull. Soc. Linn. Normandie, 8, 115-132.

Jensen F., $1974 \mathrm{a}$. Les acides gras libres des fromages danois pendant la maturation. $\mathrm{XIX}^{\mathrm{e}}$ Cong. Int. Lait., $1 \mathrm{~F}, 276$.

JENSEN R.G., 1974 b. Characteristics of the lipase from the mould Geotrichum candidum. A review. Lipids, 9, 149-157.

JoLly R.C., KosIKowSKI F.V., 1975 a. Blue cheese flavor by microbial lipase and mould spores. J. Food Sci., 40, 285-287.

Jolly R.C., KosIKowSKi F.V., 1975 b. A new blue cheese food material from ultrafiltrated skim milk and microbial enzyme-mould spore reacted fat. J. Dairy Sci., 58, 1272-1275.

Kanisawa T., IтоH H., 1984 a. Production of methyl ketone mixture from lipolyzed milk fat by fungi (studies on the production of flavors by biochemical methods - Part III). Nip. Shokuhin Kogyo Gakkaishi, 31, 477-482.

Kanisawa T., IтоH H., 1984 b. Production of methyl ketone mixture from lipolyzed milk fat by fungi isolated from blue cheese (studies on the production of flavors by biochemical methods - Part VI). Nip. Shokuhin Kogyo Gakkaishi, 31, 483-487.

KING R.D., ClEGG G.H., 1979. The metabolism of fatty acids, methyl ketones and secondary alcohols by Penicillium roqueforti in blue cheese slurries. J. Sci. Food. Agric., 30, 197-202. 
KING R.D., CLEGG G.H., 1980. The effects of casein on the metabolism of fatty acids, methyl ketones and secondary alcohols by Penicillium roqueforti in buffered solutions. J. Sci. Food. Agric., 31, 481-486.

Kinsella J.E., Hwang D.H., 1976 a. Biosynthesis of flavors by Penicillium roqueforti. Biotechnol. Bioeng., 58, 927-938.

Kinsella J.E., HWANG D.H., 1976 b. Enzymes of Penicillium roqueforti involved in the biosynthesis of cheese flavor. CRC Crit. Rev. Food Sci. Nutr., 8, 191-228.

KuzDzal W., KuzDzal-SavoIE S., 1966. Etude comparée des acides gras non volatils libres et estérifiés dans les fromages. C.R. XVII ${ }^{e}$ Cong. Int. Lait., D2, 335-342.

KuZDzal-Savore S., 1968. Application de la chromatographie sur couche mince à l'étude de la lipolyse dans les fromages. Qual. Plant. Mat. Végét., 16, 312-319.

Lamberet G., Lenoir J., 1972. Aptitude de l'espèce Penicillium caseicolum à la production d'enzymes lipolytiques. Lait, 52, 175-192.

LAMBEREt G., LenOIR J., 1976 a. Les caractères du système lipolytique de l'espèce Penicillium camemberti. Lait, 56, 119-134.

LAMBERET G., LENOIR J., 1976 b. Les caractères du système lipolytique de l'espèce Penicillium camemberti. Purification et propriétés de la lipase majeure. Lait, 56, 622-644.

Lamberet G., Auberger B., Canteri G., Lenoir J., 1982. Aptitude de Penicillium caseicolum à la dégradation oxydative des acides gras. Rev. Lait fr., (406), 13-19.

LAMBeret G., Lopez M., 1982. Activité lipolytique dans les fromages de type Camembert. Int. Dairy Cong., Vol. 1, book 2, 499-500.

Lamberet G., Menassa A., 1983 a. Purification and properties of an acid lipase from Penicillium roqueforti. J. Dairy Res., 50, 459-468.

Lamberet G., Menassa A., 1983 b. Détermination et niveau des activités lipolytiques dans les fromages à pâte persillée. Lait, 63, 333-344.

LAWRENCE R.C., 1966. The oxidation of fatty acids by spores of Penicillium roqueforti. J. gen. Microbiol., 44, 393-405.

Le Bars D., Desmazeaud M.J., Gripon J.C., Bergere J.L., 1975. Etude du rôle des microorganismes et de leurs enzymes dans la maturation des fromages. I. Fabrication aseptique d'un caillé modèle. Lait, 55, 377-389.

Le Graet Y., Lepienne A., Brule G., Ducruet P., 1983. Migration du calcium et des phosphates inorganiques dans les fromages à pâte molle de type Camembert au cours de l'affinage. Lait, 63, 317-332.

LeNorR J., 1962. La dégradation des protides au cours de la maturation du Camembert. C.R. Acad. Agric., 48, 392-399.

LENoIr J., 1970. L'activité protéasique dans les fromages à pâte molle de type Camembert. Rev. Lait. fr., (275), 231-243.

LeNorR J., Chorsy C., 1971. Aptitude de l'espèce Penicillium caseicolum à la production d'enzymes protéolytiques. Lait, $51,1-20$.

Lenoir J., Glenza A., Bergere J.L., Cerf O., Choisy C., Desmazeaud M.J., Hermier J., 1973. Les facteurs de production du système protéolytique de Penicillium caseicolum. Lait, $53,246-279$.

Lenoir J., Auberger B., 1977 a. Les caractères du système protéolytique de Penicillium caseicolum. I. Précaractérisation de l'activité exocellulaire. Lait, 57, 164-183.

Lenorr J., Auberger B., 1977 b. Les caractères du système protéolytique de Penicillium caseicolum. II. Caractérisation d'une protéase neutre. Lait, 57, 471-491.

Lenorr J., Auberger B., GrIPON J.C., 1979. Les caractères du système protéolytique de Penicillium caseicolum. III. Caractérisation d'une protéase acide. Lait, 59, 244-268.

Lenorr J., Auberger B., 1982 a. Activité de la protéase acide et de la protéase neutre de Penicillium caseicolum au cours de l'affinage du fromage de Camembert. Int. Dairy Cong., Vol. 1, book 2, 336.

LenOIR J., AUBERger B., 1982 b. Action des protéases de Penicillium caseicolum sur les caséines $\alpha_{\mathrm{S1}}$, et K. Int. Dairy Cong., Vol. 1, book 2, 335 .

LobyreVa L.B., LaRchenkova A.I., 1980. Isolation and characteristics of lipases from Penicillium roqueforti. Mikrobiol., 49, 924-930.

LOBYREVA L.B., MARCHENKova A.I., 1981. Characteristics of lipases in the cultural broth of Penicillium roqueforti. Mikrobiol., 50, 90-95. 
Menassa A., 1981. Contribution à l'étude du système lipolytique de Penicillium roqueforti. Thèse Doct. Ing., Institut National Agronomique Paris-Grignon, Paris (France).

Menassa A., Lamberet G., 1982. Contribution à l'étude du système lipolytique de Penicillium roqueforti. Caractères comparés de deux activités exocellulaires. Lait, 62, 32-43.

Meyers E., KNight S.G., 1958. Studies on the nutrition of Penicillium roqueforti. Appl. Microbiol., 6, 174-178.

Molder H.W., BrunNer J.R., Stine G.M., 1974. Extracellular protease of Penicillium roqueforti. II. Characterization of a purified enzyme preparation. J. Dairy Sci., 57, 528-534.

Moreau C., 1979. Nomenclature des Penicillium utiles à la préparation du Camembert. Lait, 59, 219-233.

Moreau C., 1980. Le Penicillium roqueforti, morphologie, intérêt en industrie fromagère, mycotoxines. Lait, 60, 254-270.

MORIHARA K., OKA T., 1973. Comparative specificity of microbial acid proteinases for synthetic peptides. III. Relationship with their trypsinogen activating ability. Arch. Biochem. Biophys., 157, 561-571.

MorRIS H.A., JEZESKI J.J., 1953. The action of microorganisms on fats. II. Some characteristics of the lipase system of Penicillium roqueforti. J. Dairy Sci., 36, 1285-1298.

Nakadai T., Nasuno S., Igushi N., 1973. Purification and properties of neutral proteinase II from Aspergillus oryzae. Agric. Biol. Chem., 37, 2703-2708.

Niki T., Yoshioka Y., AнIкo K., 1966. Proteolytic and lipolytic activities of Penicillium roqueforti isolated from blue cheese. Int. Dairy Cong, section D : 2, 531-537.

Okumura J., Kinsella J.E., 1985. Methyl ketone formation by Penicillium camemberti in model systems. J. Dairy Sci., 68, 11-15.

PAQUET J., GRIPON J.C., 1980. Intracellular peptide hydrolases of Penicillium roqueforti. Milchwissenschaft, 35, 72-74.

PHILIPp S., 1981. Penicillium roqueforti - Eigenschaften und Bedeutung für die Käseindustrie. Dtsch. Milchwirtsch., 3, 46-49.

PITT J.I., 1979. The genus Penicillium and its teleomorphic states. Eupenicillium and Talaromyces. Acad. Press., New Y rk et Londres.

RAPER K.B., Thом C., 1949. A manual of the Penicillia. Hafner Publ. Co. New York et Londres.

Samson R.A., Eckardt C., ORTh R., 1977. The taxonomy of Penicillium species from fermented cheeses. Antonie van Leeuwenhoek, 43, 341-350.

SchWARTZ D.P., PARKS O.W., 1963 a. Quantitative analysis of methyl ketones in blue cheese. J. Dairy Sci., 46, 989-990.

Schwartz D.P., Parks O.W., 1963 b. Methyl ketones in Camembert cheese. J. Dairy Sci., 46, 1136.

SchWartz D.P., Parks O.W., Boyd E.N., 1963. Methyl ketones in Roquefort cheese. J. Dairy Sci., 40, 1422-1423.

SEKINE H., 1972. Some properties of neutral proteinase I and II of Aspergillus sojae as zinc-containing metalloenzymes. Agric. Biol. Chem.., 36, 2143-2150.

Stepaniak L., Cierpikowska A., Habaj B., 1974. Activité lipolytique des souches de Penicillium roqueforti déterminée par une méthode de laboratoire et au cours de fabrication. C.R. $\mathrm{XIX}^{\mathrm{e}}$ Cong. Int. Lait., $1 \mathrm{~F}, 540$.

Trieu-Cuot P., Gripon J.C., 1981. Casein hydrolysis by Penicillium caseicolum and $P$. roqueforti. Proteinases : A study with isoelectric focusing and two dimensional electrophoresis. Neth. Milk Dairy J., 35, 353-357.

Trieu-Cuot P., ARchieri-Haze M.J., GRIPON J.C., 1982 a. Etude comparative de l'action des métalloprotéases de Penicillium caseicolum et Penicillium roqueforti sur les caséines $\alpha$ s1 et $\beta$. Lait, 62, 234-249.

Trieu-Cuot P., ARChIERI-Haze M.J., GRIPON J.C., 1982 b. Effect of aspartyl proteinases of Penicillium caseicolum and Penicillium roqueforti on casein. J. Dairy Res., 49, 487-500.

TRIEU-CuOT P., GRIPON J.C., 1982 a. A study of proteolysis during Camembert cheese ripening using isoelectric focusing and two-dimensional electrophoresis. J. Dairy Res., $49,501-510$. 
Trieu-Cuot P., Gripon J.C., 1982 b. Caractérisation de l'activité des protéases au cours de l'affinage des fromages à croûte fleurie. In Utilisation des enzymes en technologie alimentaire. Ed. P. Dupuy, Technique et Documentation, Lavoisier, Paris, 293-297.

Tsugo T., MatsuoKa H., 1962. The formation of volatile sulphur compounds during the ripening of the semi-soft white mould cheese. Int. Dairy Cong., IV, 385-392.

VANBelle M., Vervack W., Foulon M., 1978. Composition en acides gras supérieurs de quelques types de fromages consommés en Belgique. Lait, 58, 246-260.

VASSAL L., GRIPON J.C., 1984. L'amertume des fromages à pâte molle de type Camembert : rôle de la présure et de Penicillium caseicolum, moyen de la contrôler. Lait, 64, 397-417.

Vassal L., Monnet V., Le Bars D., Roux C., Gripon J.C., 1986. Influence du pH et de la Composition chimique sur la texture des fromages de type Camembert. Lait, 66, 341-351.

Veau P., Samson R.A., Breton A., 1981. Etude comparée de Penicillium roqueforti et $\boldsymbol{P}$. verrucosum var. cyclopium. Lait, 61, 370-380.

VuJicic I., DE MAN J.M., 1967. Partial glycerides in the fat of cheese. Milchwissenschaft, 22, 554-558.

Zevaco C., HeRmier J., Grippon J.C., 1973. Le système protéolytique de Penicillium roqueforti. II. Purification et propriétés de la protéase acide. Biochimie, 55, 1353-1360. 